\title{
Mesoscale convective systems and nocturnal rainfall over the West African Sahel: role of the Inter-tropical front
}

\author{
Edward K. Vizy ${ }^{1}$ (D) Kerry H. Cook $^{1}$
}

Received: 14 November 2016 / Accepted: 8 March 2017 / Published online: 18 March 2017

(C) The Author(s) 2017. This article is published with open access at Springerlink.com

\begin{abstract}
A convection-permitting regional model simulation for August 2006 and observations are evaluated to better understand the diurnal cycle of precipitation over the Sahel. In particular, reasons for a nocturnal rainfall maximum over parts of the Sahel during the height of the West African monsoon are investigated. A relationship between mesoscale convective system (MCS) activity and intertropical front (ITF)/dryline dynamics is revealed. Over $90 \%$ of the Sahel nocturnal rainfall derives from propagating MCSs that have been associated with topography in earlier studies. In contrast, in this case study, $70-90 \%$ of the nocturnal rainfall over the southern Sahel $\left(11^{\circ} \mathrm{N}-14^{\circ} \mathrm{N}\right)$ west of $15^{\circ} \mathrm{E}$ is associated with MCSs that originate less than $1000 \mathrm{~km}$ upstream (to the north and east) in the afternoon, in a region largely devoid of significant orography. This MCS development occurs in association with the Sahel ITF, combined with atmospheric pre-conditioning. Daytime surface heating generates turbulent mixing that promotes planetary boundary layer (PBL) growth accompanied by a low-level reversal in the meridional flow. This enhances wind convergence in the low-level moist layer within $2^{\circ}-3^{\circ}$ of latitude of the equatorward side of the ITF. MCSs tend to form when this vertical mixing extends to the level of free convection and is accompanied by a midtropospheric African easterly wave disturbance to the east. This synoptic disturbance enhances the vertical wind shear and atmospheric instability over the genesis location. These results are found to be robust across the region.
\end{abstract}

Edward K. Vizy

ned@jsg.utexas.edu

1 Department of Geological Sciences, Jackson School of Geosciences, The University of Texas at Austin, Austin, TX 78712, USA
Keywords Mesoscale convective system - Inter-tropical front - Dryline $\cdot$ Diurnal cycle of precipitation - West Africa $\cdot$ Sahel $\cdot$ MCS genesis

\section{Introduction}

Mesoscale convective systems (MCSs), including squall lines and African easterly wave (AEW) disturbances, are frequently observed over the West African Sahel, and past studies (Laurent et al. 1998; Laing et al. 1999; Mathon et al. 2002; Mohr 2004) indicate that up to $95 \%$ of the boreal summer rainfall over this region is associated with MCS activity. This suggests that organized systems play an important role in establishing the diurnal cycle of precipitation including nocturnal rainfall. The West African Sahel is of particular interest because evening (18Z-02Z) MCS activity and rainfall peak over much of the region during the height of the West African summer monsoon in August (Dai 2001; Mohr 2004; Zhang et al. 2016a, b). What is not completely clear is why this region is prone to nocturnal rainfall, as presumably MCSs with differing genesis locations, genesis times, size, and longevity are involved. Thus, there is a need to take a closer look at the development of individual MCSs to understand how they impact nighttime rainfall over the West African Sahel.

The purpose of this study is to understand why there is a nocturnal precipitation maximum over the southwestern Sahel during the summer, and how it relates to MCS activity. Since most areas between $11^{\circ} \mathrm{N}-14^{\circ} \mathrm{N}$ and west of $15^{\circ} \mathrm{E}$ exhibit a nocturnal rainfall maximum, the MCS-generation mechanism(s) responsible must not be local. Previous studies point to an important role for topography in generating MCSs over West Africa, but some regions well removed from significant orographic features also exhibit nocturnal 
precipitation. Here we hypothesize that the Sahel intertropical front (ITF) plays a role in generating MCSs and contributing to nocturnal rainfall for this region. The Sahel ITF separates moisture-laden air flowing off the tropical Atlantic into West Africa from dry, northerly Sahel/Saharan flow. It varies diurnally, similar to drylines observed in other regions of the world including the U.S. Great Plains of the United States (Schaefer 1974, 1986). Such features have been associated with the development of organized convection (e.g., Hamilton and Archbold 1945; Ogura et al. 1982).

In this study, high resolution (3-km resolution) regional model output along with various observational rainfall datasets are analyzed over a 1-month period (August 2006) to address these issues and better understand nocturnal rainfall and the role of Sahel ITF dynamics during the height of the West African monsoon season. The goal is to expand our fundamental understanding of MCS activity over the Sahel to improve prediction.

Section 2 provides background on MCS activity over West Africa and ITF/drylines. The experimental design is discussed in Sect. 3, including a description of the regional model simulation, observational datasets utilized, and the methodology used to identify MCSs. Results are presented in Sect. 4, while conclusions are summarized in Sect. 5.

\section{Background}

Numerous studies have identified the occurrence of organized convective systems over sub-Saharan northern Africa, including squall lines (Eldridge 1957; Desbois et al. 1988; Peters and Tetzlaff 1988; Rowell and Milford 1993) and mesoscale convective complexes (Laing and Fritsch 1993; Laurent et al. 1998). Hodges and Thorncroft (1997), Mohr et al. (1999), Mohr (2004), and Fink et al. (2006) evaluated the characteristics of these systems. MCSs are most likely to form near topographic features such as the Ethiopian Highlands, Marra Mountains, Cameroon Highlands, Jos Plateau, and Guinean Highlands, with propagation primarily westward/southwestward and lifespans ranging from a few hours to 3+ days. MCS genesis occurs most frequently in the afternoon, and the associated rainfall tends to be heavier during the early evening when the systems are typically more mature.

Longer-lasting organized precipitation systems are associated with higher values of convective available potential energy (CAPE) and strong vertical wind shear (Hodges and Thorncroft 1997; Mohr and Thorncroft 2006; Laing et al. 2008). Over the western and central Sahel, vertical wind shear is particularly strong when the low-level southerly/southwesterly monsoon flow of moist air and the West African westerly low-level jet (WAWJ; Grodsky et al.
2003, Pu and Cook 2010, 2012) is overlain by the midtropospheric African easterly jet (AEJ; Burpee 1972; Cook 1999; Parker et al. 2005a). Both of these jets exhibit distinct diurnal cycles (Parker et al. 2005b; Kalapyreddy et al. 2010). The WAWJ is strongest in the early morning hours (06Z) while the AEJ peaks later in the morning around $09 \mathrm{Z}$ and is weakest in the late afternoon when vertical mixing is strongest.

A strong relationship between MCSs and mid-tropospheric AEWs also exists. AEWs form over sub-Saharan northern Africa because of Charney-Stern instability accompanying reversals of the meridional potential vorticity gradient (Hsieh and Cook 2005, 2007, 2008). Convection is understood to be an important factor in the development of AEWs (e.g., Berry and Thorncroft 2005, 2012; Berry et al. 2007; Hsieh and Cook 2007) as strong, localized convection that characterizes the West African monsoon system can upscale and influence the regional environment and synoptic-scale growth of the AEWs (Berry and Thorncroft 2005, 2012). In turn, AEWs are an important element to creating a favorable environment of enhanced low-level convergence, rising motion, and adequate lowlevel moisture content that localized convective cells can become better organized within, and in some instances, develop into MCSs (Reed et al. 1977; Duvel 1989; Rowell and Milford 1993; Diedhiou et al. 1999; Fink and Reiner 2003). Furthermore, MCSs are observed to develop ahead of and/or behind the AEW trough depending on the season and their genesis location, with the latter more likely north of $12^{\circ} \mathrm{N}$ during the summer (Burpee 1974; Reed et al. 1977; Duvel 1989; Diedhiou et al. 1999; Fink and Reiner 2003).

Over West Africa and the Sahel, it is estimated that between 50 and $95 \%$ of the total rainfall is associated with MCSs (Laurent et al. 1998; Laing et al. 1999; Mathon et al. 2002; Mohr 2004). The wide range in estimates reflects differing observational data, analysis regions, time periods evaluated, and/or definitions of MCSs.

Less clear is how MCSs contribute to the diurnal cycle of rainfall over the Sahel. Studies by Mohr (2004), Fink et al. (2006) and Laing et al. (2012) examined this relationship and they find that the diurnal cycle of rainfall is complex, with different rainfall maxima attributed to different types of rainfall-producing systems, including propagating systems. Zhang et al. (2016a, b) show that afternoon rainfall peaks over West Africa are associated with an unstable lower-troposphere, and typically occur over orography or in regions undisturbed by nocturnal precipitation systems allowing for locally-generated instability to dominate. In contrast, they find that nocturnal rainfall peaks are primarily associated with propagating systems and generally not with local instability. Regions with nocturnal peaks are often located within $3-10^{\circ}$ of longitude downstream 
of afternoon peak areas. This demonstrates that the afternoon development of convection over the northern Sahel $\left(14^{\circ} \mathrm{N}-20^{\circ} \mathrm{N}\right)$ is physically connected with the occurrence of nighttime precipitation over the southern Sahel $\left(11^{\circ} \mathrm{N}-14^{\circ} \mathrm{N}\right)$, as precipitation systems track to the westsouthwest over the Sahel (Hodges and Thorncroft 1997).

Here we consider the environmental factors that influence the upstream generation of MCSs in regions without significant orography, and the resulting contribution to nocturnal rainfall. One such factor is associated with the Sahel ITF, or dryline (Eldridge 1957) which separates the moist West African monsoon air from dry Sahel/Saharan air. The moist layer is shallowest near the frontal boundary, but deepens equatorward. This feature is identified in the near-surface moisture field by a sharp, negative meridional moisture gradient, and it has a strong seasonal cycle that moves it from $7^{\circ} \mathrm{N}$ in January to $20^{\circ} \mathrm{N}$ in August.

While drylines are typically associated with atmospheric conditions favorable for the development of convection, it does not necessarily mean that it is the triggering mechanism (Ogura et al. 1982; Carlson et al. 1983; Benjamin and Carlson 1986). As discussed in the above-mentioned studies, the primary role of the dryline is to provide a restraining inversion for lower-tropospheric turbulence that suppresses the release of convective instability too early in the day. Convection is more commonly thought to initiate near a dryline either by dry convective-scale motions arising from daytime surface heating of the planetary boundary layer (PBL), or by mesoscale thermally-direct vertical circulations driven by differential heating due to sloping terrain and/or the non-homogeneous vegetation/soil conditions (Carlson et al. 1983; Trier et al. 2004, 2015).

The Sahel ITF exhibits a distinct diurnal cycle in the summer (Parker et al. 2005b), analogous to drylines in other regions of the world (Shaefer 1974, 1986). During the morning, the surface warms faster where the moist layer is shallow near the ITF compared to farther south where the moist layer is deeper. Thus, it takes less time to vertically mix the moist air in the boundary layer close to the front. As heating continues during the day, the deeper moist layers farther south are eventually mixed, resulting in the southward movement of the ITF from around $19^{\circ} \mathrm{N}$ in the early morning to $16^{\circ} \mathrm{N}$ in the afternoon. When the heating and vertical mixing are insufficient, this southward movement halts. After sunset, vertical mixing weakens as the atmosphere becomes stably stratified. The low-level flow responds by accelerating toward the Saharan thermal low to the north, enhancing low-level moisture advection to the north and, thereby, the nocturnal northward retreat of the ITF.

Since the ITF is a semi-permanent summertime feature over the Sahel while convective activity over the Sahel is sporadic, other environmental factors are likely important.
To our knowledge this has not been explicitly discussed for the Sahel but, for the Great Plains, distinctions between quiescent and synoptically-active drylines have been made (Hane 2004; Schultz et al. 2007). Dryline events associated with synoptic-scale forcing can behave differently from quiescent drylines because the synoptic-scale processes can be more influential than the small-scale turbulent processes typically associated with quiescent drylines. It is not difficult to imagine a similar relationship over the Sahel, where synoptic AEW disturbances are known to occur (Reed et al. 1977; Diedhiou et al. 1999). That being said, the scale of the environmental forcing differs between the Great Plains and West Africa as the synoptic environment of the Great Plains is super-charged compared to West Africa.

To improve our fundamental understanding of the relationships among the ITF, MCSs, and nocturnal rainfall over the West African Sahel during the peak of the West African monsoon season, we adopt a regional focus. The analysis is focused on a region of the western Sahel observed to have a distinct nocturnal rainfall maximum before generalizing to larger space scales.

\section{Experimental design}

\subsection{Model description and simulation design}

A high-resolution regional model simulation using the National Center for Atmospheric Research (NCAR) Weather Research and Forecasting Model Version 3.4.1 (WRF; Skamarock et al. 2005) is utilized. The simulation uses a triple-nested domain configuration with one-way nesting, as shown in Fig. 1. The outer domain has $27-\mathrm{km}$ resolution and encompasses almost all of Africa north of the equator to minimize the effects of prescribed lateral boundary constraints over the region of interest. The 9-km domain is focused more on Africa between the equator and $30^{\circ} \mathrm{N}$, and its lateral boundary conditions are determined from the $27-\mathrm{km}$ domain. A $3-\mathrm{km}$ domain is imbedded within the 9-km domain covering all of West Africa and the Sahel; tracking and analysis of MCSs is conducted at this resolution. Studies (e.g., Laing et al. 2012; Marsham et al. 2013; Taylor et al. 2013; Pearson et al. 2014; Maurer et al. 2016; Zhang et al. 2016b) have demonstrated using regional models at convection-permitting resolutions can more realistically represent the physical processes associated with the development of deep-convection over West Africa, including the diurnal cycle of rainfall.

Physical parameterizations are the same for all three domains, and include the Thompson microphysics (Thompson et al. 2004), Rapid Radiative Transfer Model (RRTM) longwave radiation (Mlawer et al. 1997), Dudhia shortwave radiation (Dudhia et al. 1989), Monin-Obukhov 


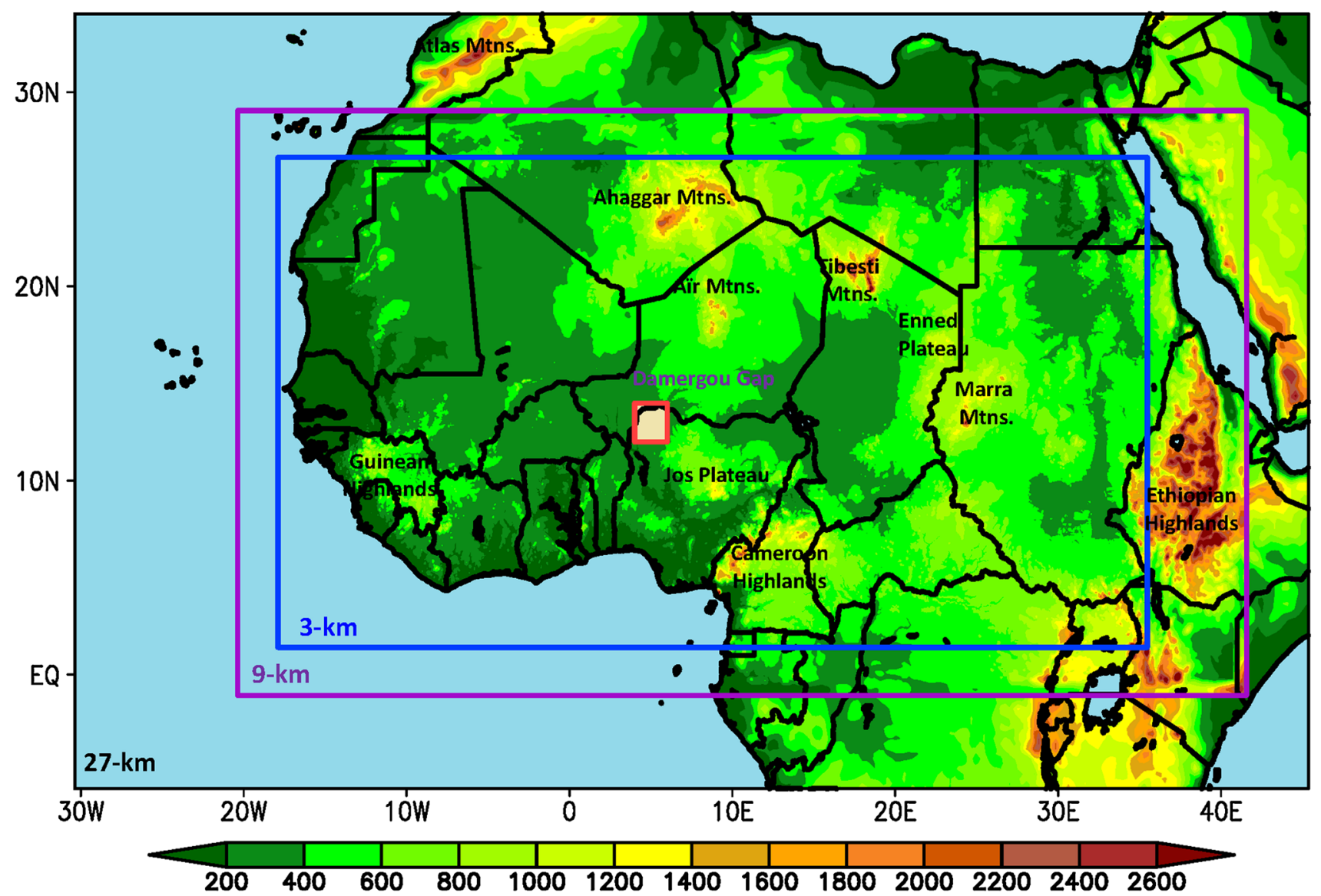

Fig. 1 WRF model topography (meters) as resolved in the (black) 27-km, (purple) 9-km, and (blue) 3-km domains. The red box denotes the position of the analysis region used in this study

surface layer, the unified Noah land surface model (Chen and Dudhia 2001), and the Yonsei University planetary boundary layer (Hong et al. 2006) parameterizations. The 27- and 9-km domains utilize the new Kain-Fritsch cumulus convection parameterization (Kain 2004), but cumulus convection parameterization is turned off for the $3-\mathrm{km}$ domain since its resolution is sufficient to permit explicit convection. These parameterizations are chosen based on studies that demonstrate they can yield a realistic representation of African climate and weather at various timescales (Vizy and Cook 2009; Laing et al. 2012; Vizy et al. 2013, 2015; Crétat et al. 2014, 2015). The model time steps for the $27-\mathrm{km}, 9-\mathrm{km}$, and 3-km domains are 90, 30, and $10 \mathrm{~s}$, respectively. Model output is saved every $30 \mathrm{~min}$, sufficient for tracking the lifecycles of MCSs.

The model simulation is run for a 1-month period during the height of the summer West African monsoon season, August 2006. This choice coordinates with Zhang et al. (2016a, b), who evaluated the diurnal cycle of rainfall in observations and high-resolution modeling simulations for this African Monsoon Multidisciplinary Analysis special observing period (AMMA SOP), and find nocturnal precipitation maxima over the southern Sahel between $11^{\circ} \mathrm{N}-14^{\circ} \mathrm{N}$ in the TRMM observations [see Fig. 6 in Zhang et al. (2016a)]. This nocturnal precipitation maximum is also identifiable in the 1998-2013 TRMM climatology [see Fig. 4 in Zhang et al. (2016a)], although it is less clear in the climatology due to interannual variability.

The simulation is initialized on 12Z 30 July 2006 and run through 00Z 1 September 2006 using initial conditions derived from the European Centre for MediumRange Weather Forecasts ERA-Interim (ERAI; Dee et al. 2011) reanalysis in all domains; ERAI-derived 6-hourly lateral boundary conditions force the $27-\mathrm{km}$ domain. The first 36-h are devoted to model spin-up and are discarded. 6-hourly SSTs are prescribed from ERAI.

Given that the simulation is free-running and does not use nudging, the simulation should not be expected to simulate the exact timing and location of every observed August 2006 rainfall event. We choose not to use a nudging approach because we are interested in understanding the physical processes that lead to the development of MCSs, with the processes under the control of the governing equations and not externally-prescribed boundary conditions. 
The model output is evaluated according to whether it can simulate reasonable distributions of MCSs and the observed diurnal cycle of rainfall, rather than whether it can capture particular storms.

\subsection{Observational rainfall datasets}

Two high-resolution, gridded, observational rainfall datasets are used. One is the National Oceanic and Atmospheric Administration (NOAA) Climate Prediction Center morphing technique precipitation dataset version 1.0 (CMORPH; Joyce et al. 2004) which is available online (http://www.cpc.noaa.gov/products/janowiak/cmorph_ description.html). This $8-\mathrm{km}$ resolution dataset yields rainfall estimates at 30-min intervals by taking estimates derived from passive microwave observations and extrapolating them backward and forward in time via spatial propagation information obtained from geostationary Infrared (IR) satellite data. Here, we utilize the bias corrected version.

The other precipitation dataset is the NASA Tropical Rainfall Measuring Mission 3B42 version 7 (TRMM; Huffman et al. 2007) rainfall dataset available online (http://disc.sci.gsfc.nasa.gov/precipitation/documentation/ TRMM_README/TRMM_3B42_readme.shtml). This $0.25^{\circ}$ resolution rainfall product blends microwave and IR satellite precipitation estimates to create a 3-hourly rainfall product.

CMORPH and TRMM datasets are used to evaluate the reliability of the simulation, as they both have been shown to provide realistic estimates of the diurnal cycle of rainfall over Africa when compared to ground truth (Pfeifroth et al. 2016). The temporal and spatial resolutions of CMORPH are close to those of the regional model. TRMM is coarser in both spatial and temporal resolution, so more caution must be taken when comparing to the model output. Because of this issue, TRMM is primarily used here to bracket observational uncertainty.

\subsection{Methodology}

The results of Zhang et al. (2016a, b) show that much of the southern Sahel, between $8^{\circ} \mathrm{W}$ and $20^{\circ} \mathrm{E}$, has a nocturnal rainfall maximum during August 2006. To focus a detailed, physical analysis of the relationship among MCSs, the ITF, and the diurnal cycle of rainfall over the southern Sahel, a $2^{\circ}$ longitude $\times 2^{\circ}$ latitude analysis region is selected, as shown in Fig. 1. The purpose of a $2^{\circ} \times 2^{\circ}$ region is to capture MCSs traversing over the area. The region is in northwestern Nigeria, between $4^{\circ} \mathrm{E}-6^{\circ} \mathrm{E}$ and $12^{\circ} \mathrm{N}-14^{\circ} \mathrm{N}$. Given the very large number of MCSs generated in the Sahel in summer, the choice of a small region allows us to examine the total population of MCSs that are associated with nocturnal precipitation in this region. The findings are evaluated at the end of Sect. 4 to apply the results to the entire southwestern Sahel.

Based on previous definitions of MCSs (Houze 1993; Mohr and Zipser 1996; Nesbitt and Zipser 2003), we define MCSs at 30-min time steps for the model output and CMORPH and at 3-hourly time steps for TRMM as rainfall systems with a contiguous spatial area encompassed by the $5 \mathrm{~mm}$ day $^{-1}$ rainfall contour that is greater than $2000 \mathrm{~km}^{2}$. The $5 \mathrm{~mm} \mathrm{day}{ }^{-1}$ rainfall contour threshold is somewhat arbitrary, but it eliminates the influence of light rainfall activity. We tested the sensitivity to this choice by assuming different thresholds between 1 and $10 \mathrm{~mm} \mathrm{day}^{-1}$. The threshold value chosen does not make a large difference in the number of MCSs identified, but when a smaller threshold is selected MCS size estimations are larger. This decision regarding the intensity threshold does not change the primary results of this study.

The criterion that the MCS must have a minimum contiguous area of $2000 \mathrm{~km}^{2}$ follows from MCS size estimates employed by other studies (e.g., Houze 1993; Mohr and Zipser 1996; Nesbitt and Zipser 2003). The threshold of $2000 \mathrm{~km}^{2}$ represents the population of relatively large MCSs in terms of the distribution of organized convection spectrum, but not necessarily all possible MCSs. In the model simulation, this amounts to having at least 223 contiguous grid points that meet the $5 \mathrm{~mm} \mathrm{day}^{-1}$ threshold. For CMORPH and TRMM, MCSs will have at least 32 and 3 grid points, respectively, with rainfall above the threshold rate.

After all of the MCSs are identified, they are subjectively tracked forward and backward in time to identify their lifespan from genesis to termination. Genesis is defined as the time when a precipitation system first meets the criterion to be a MCS, and termination occurs when a system no longer meets the criterion.

\section{Results}

Figure 2a lists the MCS events that generate rainfall in the analysis region in the simulation, and the map indicates their genesis (red) and termination (blue) locations. 16 MCSs events with lifespans varying between 11 and over $70 \mathrm{~h}$ are identified. A large fraction (11 out of 16) of MCSs originate over northwestern Nigeria (north of $11^{\circ} \mathrm{N}$ ) or Niger. The remaining 5 events originate farther east over easternmost Nigeria, Chad, or Sudan. The termination locations are primarily to the west and southwest of the analysis region. MCSs reach as far west as western Mali and Senegal, but 9 of the 16 systems decay over Ivory Coast, Ghana, Togo, Benin, and southwestern Nigeria. 
Fig. 2 August 2006 genesis (red) and decay (blue) locations for MCSs that traverse the analysis region (yellow box) for a WRF 3-km resolution simulation, and b CMORPH, and $\mathbf{c}$ TRMM rainfall datasets. MCS genesis and decay times in addition to the total MCS lifespan are provided for WRF, CMORPH, and TRMM

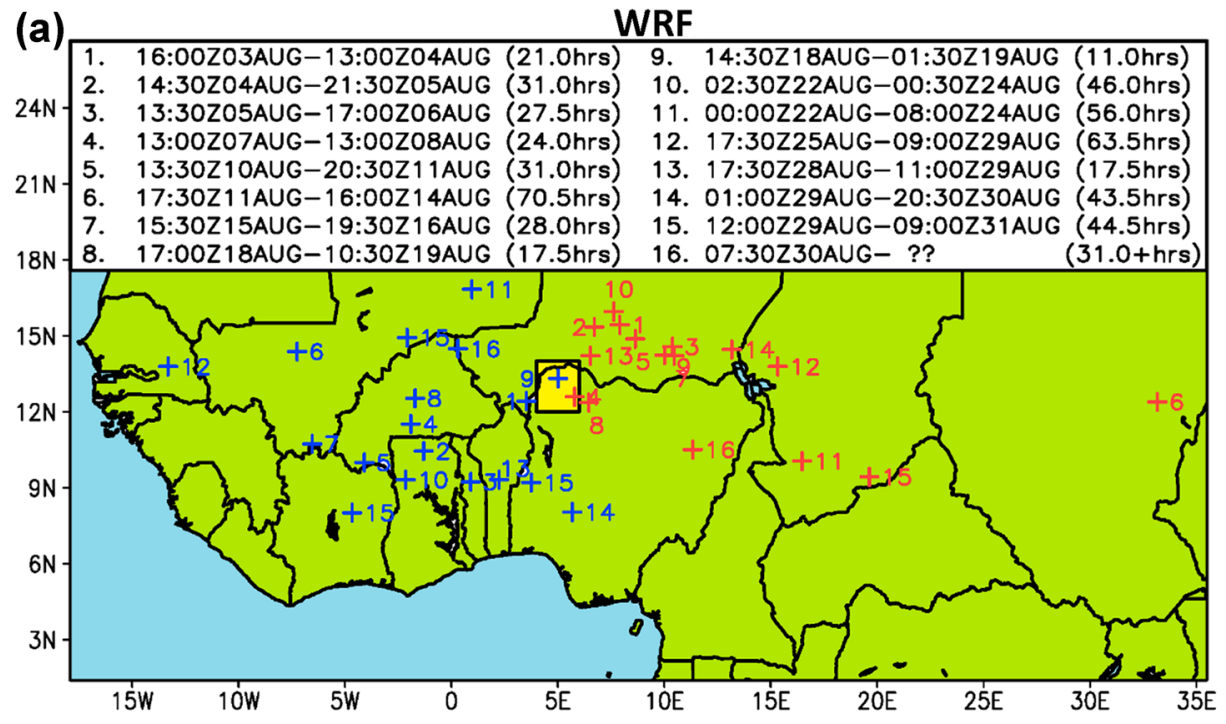

(b)

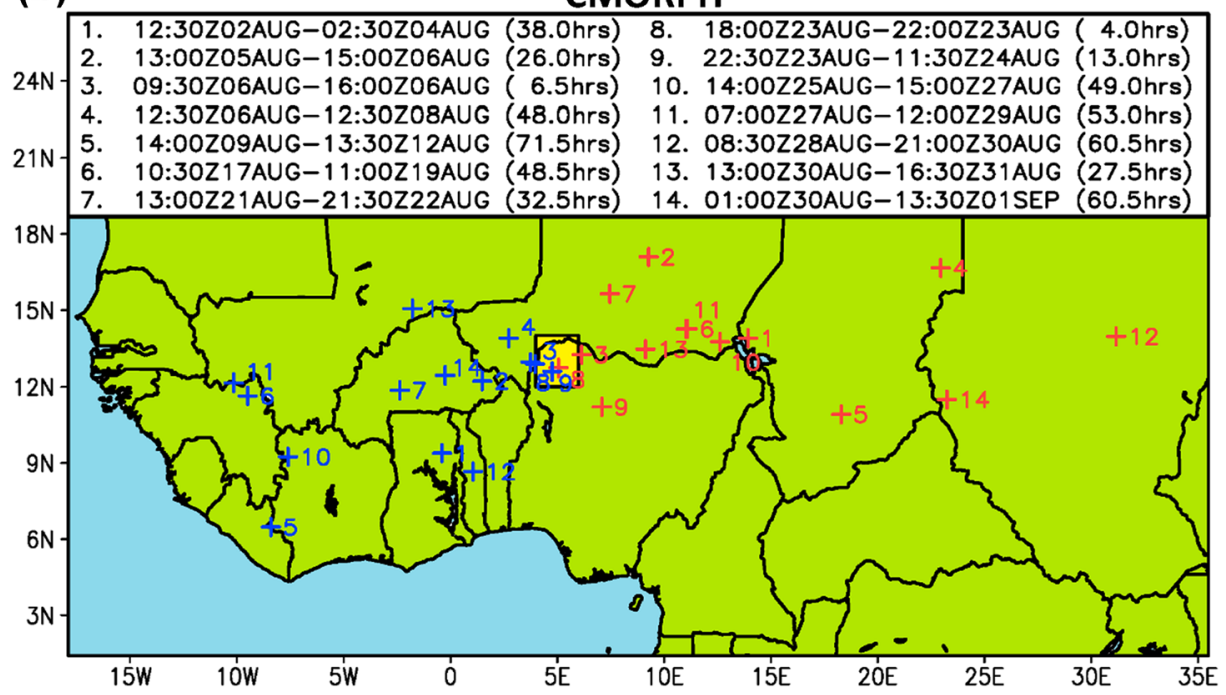

(c)

TRMM

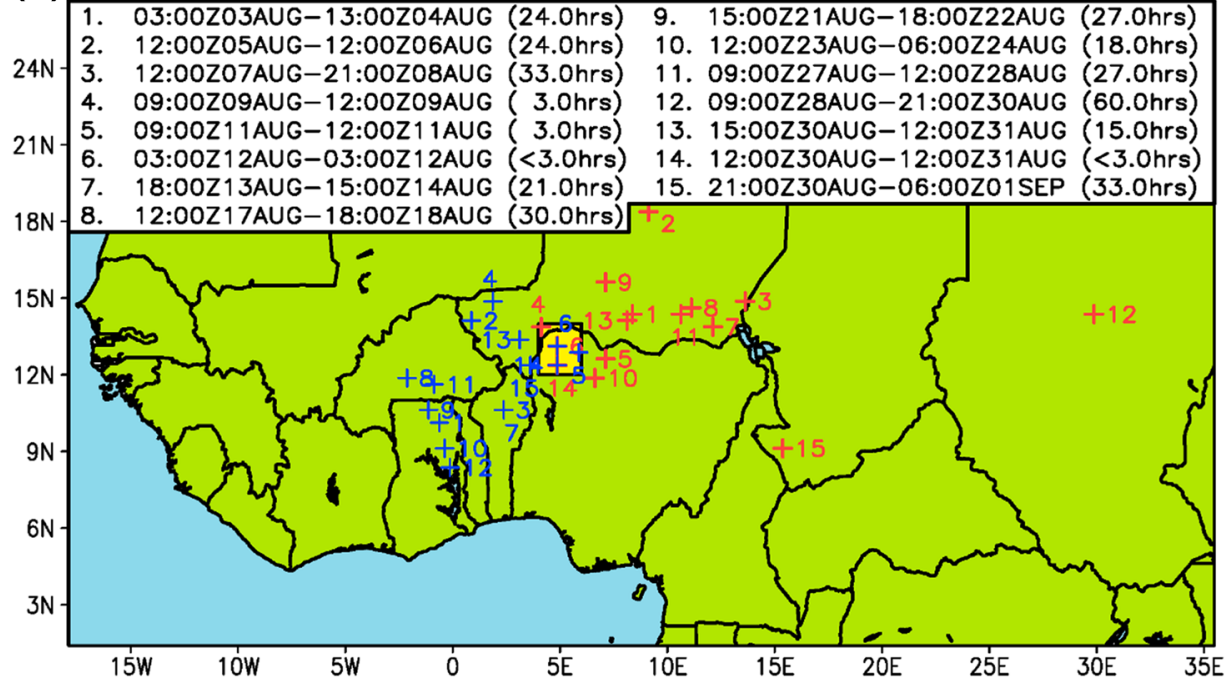


Figure 2b, c list the August 2006 MCSs and plot their genesis and termination locations from CMORPH and TRMM, respectively. For CMORPH (Fig. 2b), 14 MCS events are identified. 10 of the 14 events originate over northwestern Nigeria or Niger, while the other 4 events originate over Chad or Sudan, similar to the model simulation. Fewer MCSs die along the Guinean Coast, as only 4 of the 14 MCSs are observed to terminate here in CMORPH. Instead, a couple more events appear to be shorter-lived (i.e., less than $10 \mathrm{~h}$ ) than in the model, with lysis over southwestern Niger or Burkina Faso instead. 2 MCSs do not die out until reaching far southwestern Mali, consistent with the model simulation.

For TRMM (Fig. 2c), 15 MCS events are identified. 13 of these events originate over northwestern Nigeria and Niger, similar to CMORPH and model. The other two MCSs originate over the central and eastern Sahel. TRMM termination locations are clustered immediately to the west and southwest of the analysis region, with no MCSs tracking west of $3^{\circ} \mathrm{W}$. These differences between CMORPH and TRMM are likely related to the relative spatiotemporal coarseness of TRMM, as it is less accurate to track smaller MCSs in TRMM.

The above results indicate that the $3-\mathrm{km}$ regional model simulation realistically simulates the number of MCSs that influence the analysis region for August 2006. Furthermore, the genesis and lysis locations of these simulated MCSs generally agree with the observations, giving us confidence that the model is realistically simulating MCS lifecycles in this area.

It is clear from Fig. 2 that $70-80 \%$ of the MCSs originate to the north and east over the central Sahel of Niger in relatively close proximity (within $1000 \mathrm{~km}$ ) to the analysis region. The remaining MCSs originate much farther east (i.e., $>1000 \mathrm{~km}$ away) over Chad and Sudan. The evaluation of these systems is organized based on their genesis proximity to the analysis region as well as the time of day for genesis.

Figure $3 \mathrm{a}, \mathrm{b}$ show the temporal evolution of MCS total area and total rainfall over the lifespan of the 11 simulated MCSs that originate within $1000 \mathrm{~km}$ of the analysis region, respectively. A bolding of the line denotes when (a) MCS genesis cases $<1000 \mathrm{~km}$ : total area

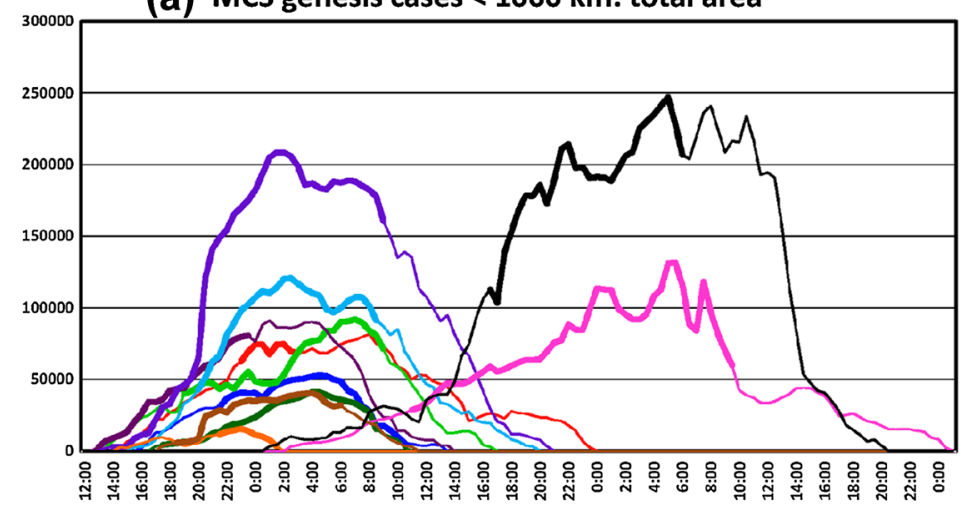

(b) MCS genesis cases $<1000 \mathrm{~km}$ : total rainfall

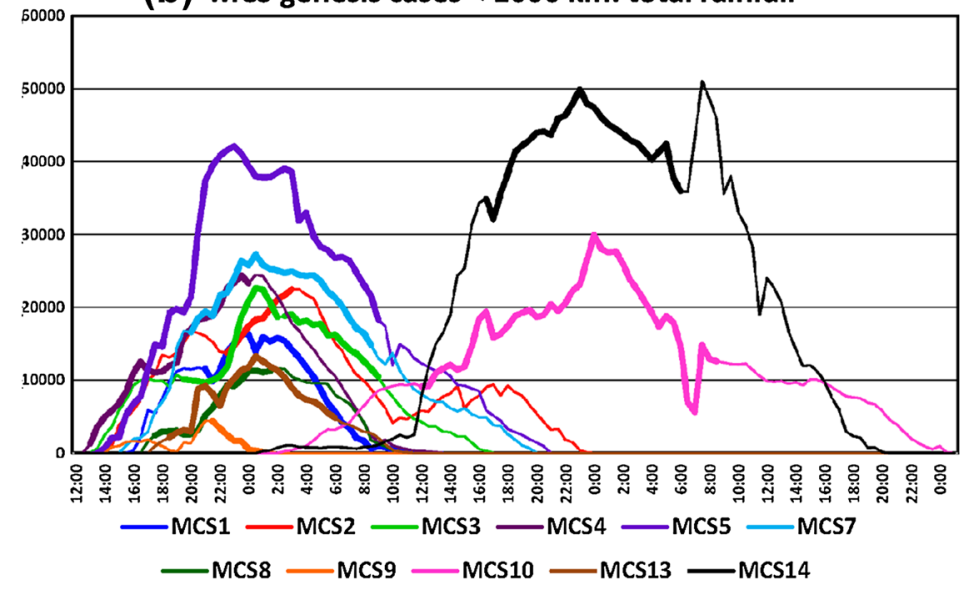

(c) MCS genesis cases $>1000 \mathrm{~km}$ : total area

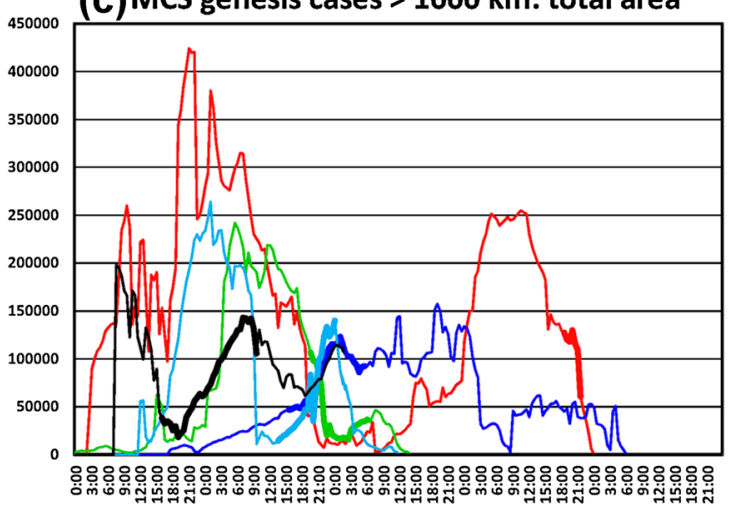

(d) RG MCS genesis cases $>1000 \mathrm{~km}$ : tot. rainfall

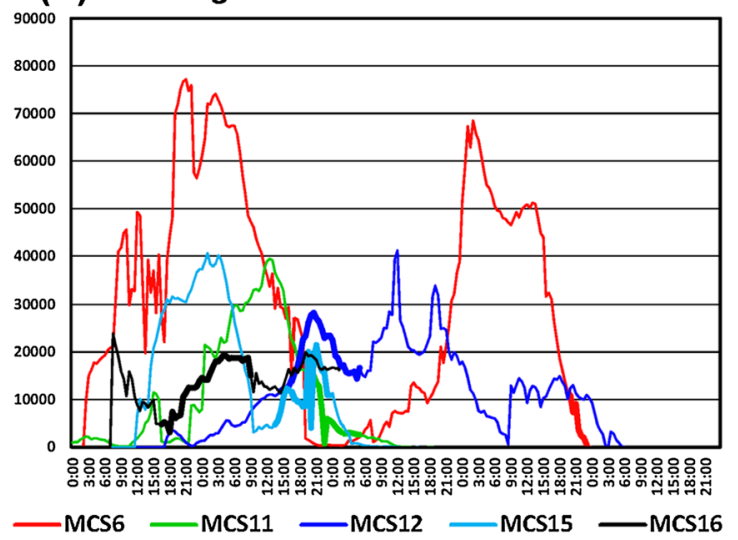

Fig. 3 WRF 3-km a total MCS area $\left(\mathrm{km}^{2}\right)$ and $\mathbf{b}$ total rainfall (mm) for MCS genesis cases $<1000 \mathrm{~km}$ away from analysis region. Additionally, $\mathbf{c}$ total MCS area and $\mathbf{d}$ total rainfall for MCS genesis cases
$>1000 \mathrm{~km}$ away from analysis region. Thickened lines denote when MCS is over the analysis region shown in Fig. 1 
the MCS is located over the analysis region (Fig. 1). 9 of the 11 MCSs originate during the afternoon. They form between 13Z-18Z, and generally peak in size between 0Z-7Z. The peak in total rainfall happens a little earlier, generally between $22 Z-2 Z$, while the MCSs die off during the following day, usually sometime between 10Z-20Z. The MCS area maximum occurs when the MCS is over the analysis region for 8 of the 9 daytime events, with MCS4 the lone exception. The rainfall maxima occur over the analysis region for all 9 cases. This indicates that these MCSs are mature when they traverse the analysis region. The average duration of these events is $23 \mathrm{~h}$, which is shorter than the $31 \mathrm{~h}$ estimated from CMORPH. MCS phase speeds range between 8 and $14 \mathrm{~m}$ $\mathrm{s}^{-1}$, again consistent with CMORPH estimates.

2 of the 11 simulated MCSs (MCS10 and MCS14) form in the middle of the night. Genesis occurs around $2 Z$, with a steady increase in size until $4 Z-8 Z$ the following morning, 26-30 h after genesis. Rainfall follows a similar temporal evolution, but with the maximum occurring a few hours before the size maximum, around 23Z-2Z, 21 to $24 \mathrm{~h}$ after genesis. Similar to the daytime genesis cases, the maxima in size and total rainfall occurs when the system is over the analysis region. Nighttime genesis events are slightly larger and associated with more total rainfall, but this is not a robust conclusion given the small sample size. The average MCS phase speed is $7 \mathrm{~m} \mathrm{~s}^{-1}$, slower than the daytime genesis events.

Figure $3 \mathrm{c}, \mathrm{d}$ show the total area and total rainfall for the 5 MCSs that originate more than $1000 \mathrm{~km}$ from the analysis region in the simulation. Note that the axes scales differ from Fig. 3a, b, as these MCSs achieve larger sizes and produce more rainfall. These are the longer-lived systems, persisting for an average of $59 \mathrm{~h}$, which is consistent with CMORPH (Fig. 2b). MCS6 and MCS15, which originate farthest east (Fig. 2a), have multiple nocturnal size and rainfall maxima and they are strongest well east of the analysis region. MCS11, MCS12, and MCS16, which originate over western Chad or easternmost Nigeria, have sizes and precipitation maxima smaller than MCS6 and MCS15. 4 out of 5 of these MCSs (all except MCS15) are associated with convective activity over the analysis region during the evening/nighttime hours. MCS phase speeds range from $9 \mathrm{~m} \mathrm{~s}^{-1}$ and $15 \mathrm{~m} \mathrm{~s}^{-1}$, again consistent with CMORPH estimates.

Atmospheric conditions near genesis time are examined to better understand why these MCSs form. Our evaluation emphasizes synoptic forcing conditions, atmospheric moisture content, atmospheric instability, and vertical shear since these factors are known to be important for the development of organized convection.

\subsection{Conditions for MCSs with daytime genesis $<1000 \mathrm{~km}$ away from analysis region}

Synoptic conditions prior to genesis for each of the 9 cases are characterized by the 700-hPa geopotential height anomalies at $12 \mathrm{Z}$ on genesis day in Fig. 4. For each 30-minute interval of the day, height anomalies are calculated by subtracting the appropriate August 2006 monthly mean value. MCS1, MCS2, and MCS3 genesis (Fig. 4a-c) are associated with a broad area of negative height anomalies over the central Sahara north of $20^{\circ} \mathrm{N}$, signifying a weaker midtropospheric Saharan anticyclone. The anomalous height field also indicates the presence of a AEW disturbance between $8^{\circ} \mathrm{N}-15^{\circ} \mathrm{N}$ to the east (upstream) of the genesis location that slowly moves westward over 3 days. No AEW disturbances are discernable near the genesis location of MCS4 (Fig. 4d), suggesting that this event is likely associated with locally-forced convection due to daytime heating instead of synoptically-forced convection. MCS5 (Fig. 4e), MCS7 (Fig. 4f), and MCS13 (Fig. 4h) are also associated with AEW disturbances to the east of the genesis location but, unlike MCS1, MCS2, and MCS3, there are generally positive height anomalies over the central Sahara, indicating a stronger mid-tropospheric Saharan anticyclone for these cases. Finally, MCS8 and MCS9, which occur on the same day, are associated with an AEW disturbance between $10^{\circ} \mathrm{N}-15^{\circ} \mathrm{N}$ to the west of the genesis location over southwestern Mali, and anomalous positive heights over northernmost Niger and the central Sahara north of $18^{\circ} \mathrm{N}$.

These results suggest that both the southern $\left(8^{\circ} \mathrm{N}-15^{\circ} \mathrm{N}\right)$ and northern $\left(16^{\circ} \mathrm{N}-22^{\circ} \mathrm{N}\right)$ mid-tropospheric disturbance tracks play a role in genesis. This is consistent with other studies (Diedhiou et al. 1999; Fink and Reiner 2003) that indicate climatologically, AEWs occur both on the equatorward and poleward flanks of the AEJ, which is centered between $12^{\circ} \mathrm{N}-15^{\circ} \mathrm{N}$ in August. Daytime genesis over southern Niger is more common (six out of nine cases) when there is a mid-tropospheric disturbance to the east of the genesis location in the southern disturbance track. The influence of northern track disturbances is less clear because the three cases with robust negative anomalies over the central Sahara (MCS1, MCS2, and MCS3) also coincide with a disturbance in the southern track. Furthermore, other cases (MCS5, MCS7, and MCS13) result in MCS genesis over Niger despite positive mid-tropospheric height anomalies over the central Sahara.

Circulation anomalies associated with these midtropospheric disturbances change atmospheric moisture content. A mid-level disturbance to the east of the genesis location enhances the mid-level northerly flow of drier, Sahel/Saharan air over the genesis location and is associated with stronger instability. This is assessed by evaluating CAPE for a parcel at $925 \mathrm{hPa}$ at $12 \mathrm{Z}$ on 

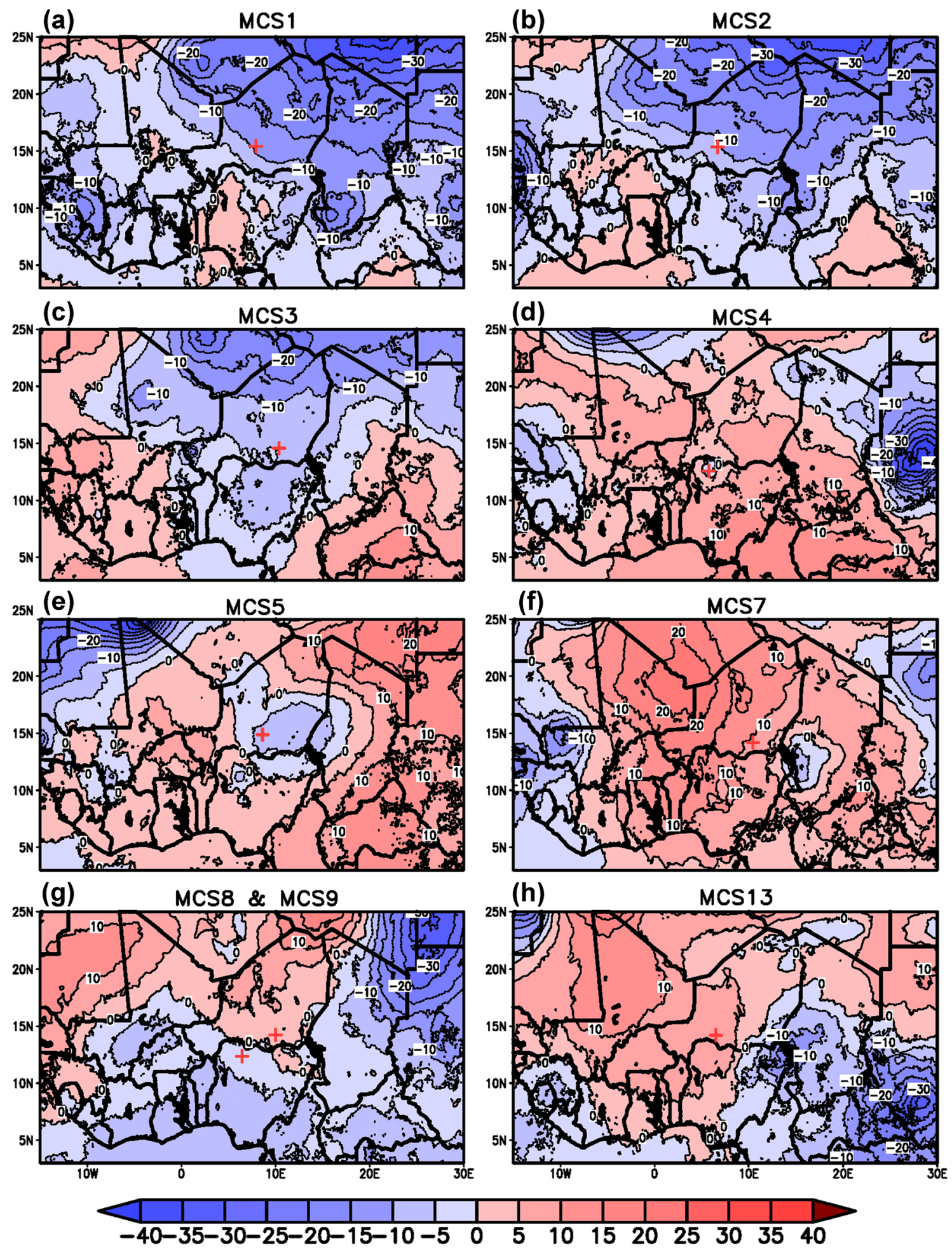

Fig. $4700 \mathrm{hPa}$ geopotential height anomalies (m) at 12Z on genesis day for a MCS1, b MCS2, c MCS3, d MCS4, e MCS5, f MCS6, g MCS8 and MCS9, and $\mathbf{h}$ MCS13. Crosshairs denote MCS genesis location

genesis day for each event (Fig. 5). Overall, a swath of higher CAPE values extending over the southern Sahel from $10^{\circ} \mathrm{N}-16^{\circ} \mathrm{N}$ occurs at $12 \mathrm{Z}$. For some cases this swath extends further east (MCS8 and MCS9), while other days it only extends into western Niger (MCS2).

For all 9 cases, CAPE values in the vicinity of the genesis 

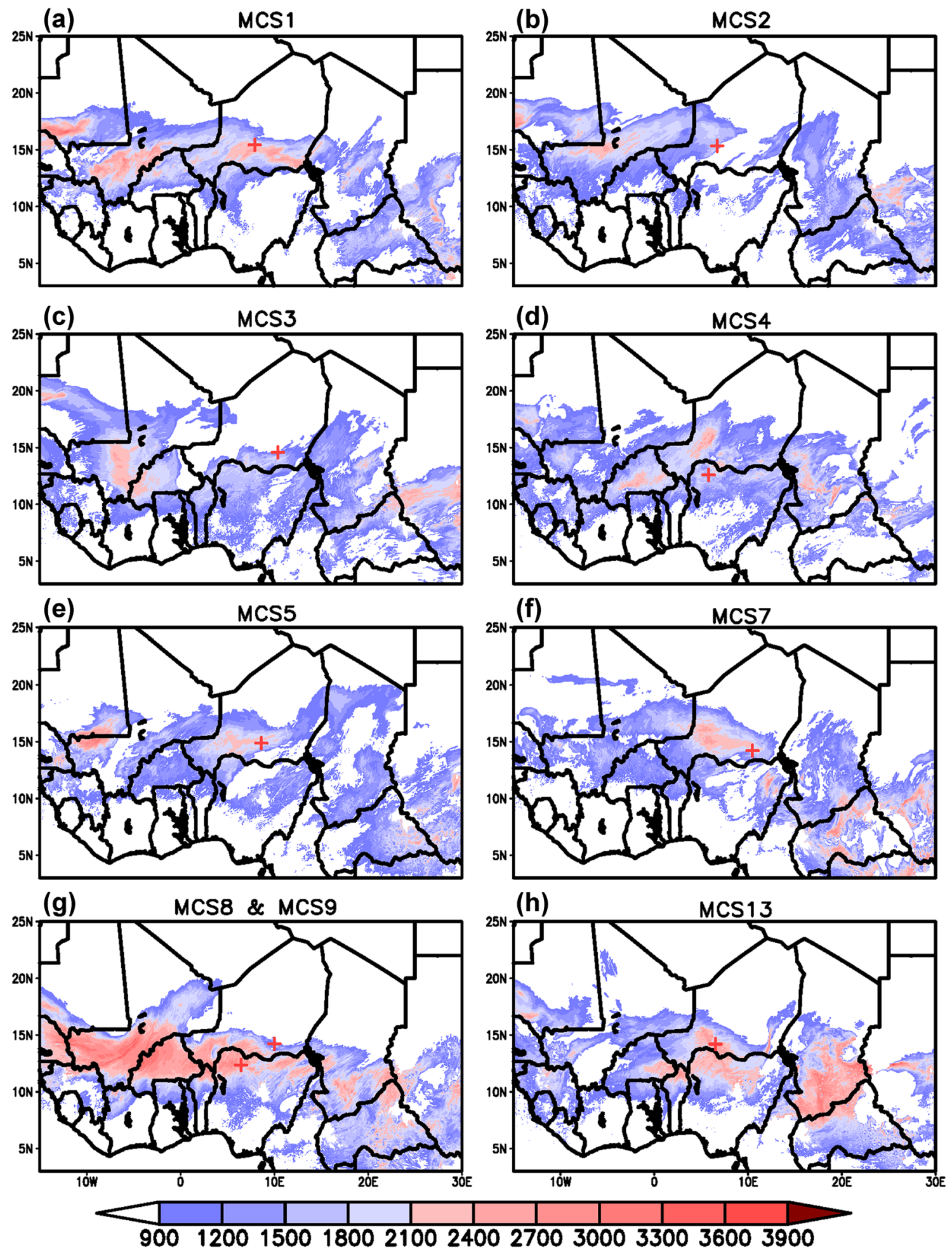

Fig. $5925 \mathrm{hPa}$ CAPE $\left(\mathrm{J} \mathrm{kg}^{-1}\right)$ at $12 \mathrm{Z}$ on genesis day for the cases a MCS1, b MCS2, c MCS3, d MCS4, e MCS5, f MCS6, g MCS8 and MCS9, and $\mathbf{h}$ MCS13. Crosshairs denote MCS genesis location

location are greater than $1200 \mathrm{~J} \mathrm{~kg}^{-1}$, indicating the presence of at least moderate instability. For MCS1, MCS5, MCS7, MCS8, MCS9, and MCS13, values are greater than $2400 \mathrm{~J} \mathrm{~kg}^{-1}$, indicating strong instability. Thus, in all cases the environment is sufficiently unstable to support the development of convection.

At low-levels there is a relatively deep moist layer near $10^{\circ} \mathrm{N}$ that becomes progressively shallower to the north. 
This sharp meridional moisture gradient in close proximity to the genesis region of southern Niger has a diurnal cycle analogous to drylines observed over the south-central Great Plains of the U.S. (Schaefer 1986). While thunderstorms tend to develop in their vicinity, drylines are not the triggering mechanism for convection (e.g., Ogura et al. 1982; Carlson et al. 1983; Trier et al. 2015). However, the dryline's proximity can be an important environmental factor because convective systems that form near them tend to become stronger and better organized (Rhea 1966). In the case of southern Niger, the modest elevation rise within the Damergou Gap northward to the Air Mountains and the Koutous Plateau $\left(\sim 14.5^{\circ} \mathrm{N}, 10.25^{\circ} \mathrm{E}\right)$ provide the focal point for the initiation of convection for this region.

The 925-hPa dewpoint temperature characterizes the low-level moisture content. Figure $6 \mathrm{a}-\mathrm{h}$ shows the longitudinally averaged diurnal cycle of the $925 \mathrm{hPa} 13{ }^{\circ} \mathrm{C}$ isodrosotherm in the vicinity of the MCS genesis region for each of the 9 MCS event days. Longitudinal averaging is conducted over a $2^{\circ}$ window centered on the MCS genesis longitude except for MCS8 and MCS9, where a $5^{\circ}$ longitude window is used to account for the two MCSs that form on this day. The $13{ }^{\circ} \mathrm{C}$ isodrosotherm is used because it is the threshold value that supports thunderstorm activity with strong rotation (Williams 1976). A sufficient, lowlevel moisture supply for convection occurs equatorward of this threshold value. A clear diurnal cycle occurs in all cases, with the $13{ }^{\circ} \mathrm{C}$ isodrosotherm farthest north around $9 \mathrm{Z}$ and farthest equatorward around 17Z. The north/south peak amplitudes can deviate somewhat from one another, but typically fall between $15^{\circ} \mathrm{N}$ and $20^{\circ} \mathrm{N}$.

Crosshairs on Fig. 6a-h indicate the latitudinal position and time of genesis for each of the 9 MCSs. MCS genesis occurs shortly after $12 \mathrm{Z}$ coinciding with when the $13{ }^{\circ} \mathrm{C}$ isodrosotherm has shifted to its afternoon equatorward position. Furthermore, genesis generally occurs equatorward, but close to the $13{ }^{\circ} \mathrm{C}$ isodrosotherm, usually within $2^{\circ}$ of latitude. Exceptions are MCS4 and MCS8, which develop farther from the ITF boundary.

The abrupt equatorward shift of the $13^{\circ} \mathrm{C}$ isodrosotherm coincides with a mid- to late-morning breakdown of the nocturnal capping inversion and a rapid deepening of the planetary boundary layer (PBL) to the point where it exceeds the height of the level of free convection (LFC) for a period of time. The red shading in Fig. 6a-h indicates where/when the longitudinally averaged PBL height-LFC difference is positive (i.e., where/when the PBL height extends beyond the LFC). For all nine cases this occurs for a brief period in time prior to MCS genesis, and coincides with when the $13{ }^{\circ} \mathrm{C}$ isodrosotherm shifts equatorward in the early afternoon. MCS genesis occurs usually within $3 \mathrm{~h}$ after when the PBL height first exceeds the LFC at the genesis latitude.
Diurnal changes in the PBL and ITF are accompanied by variations in the low-level meridional flow which can be associated with changes in low-level wind convergence. Figure $7 \mathrm{a}-\mathrm{h}$ show the longitudinally averaged diurnal cycle of the $925-\mathrm{hPa}$ wind convergence (shading) with the locations of the $925 \mathrm{hPa}$ meridional wind component $0 \mathrm{~m} \mathrm{~s}^{-1}$ boundary (purple) and $925 \mathrm{hPa} 13{ }^{\circ} \mathrm{C}$ isodrosotherm boundary (green) superimposed on top. Stippling denotes when the meridional wind component is northerly.

For the individual MCS events, all form in environments where there is localized low-level wind convergence prior to development at the genesis latitude. Exactly how long the low-level wind is convergent varies, ranging from sunrise for MCS1, MCS2, and MCS7, to less than $3 \mathrm{~h}$ for MCS4 and MCS9. If the $925 \mathrm{hPa} 0 \mathrm{~m} \mathrm{~s}^{-1}$ meridional wind boundary is used to approximate the daytime position of the ITF, then we find that MCS genesis occurs in close proximity to the ITF gust frontal boundary for at least 6 of the cases (MCS1, MCS2, MCS3, MCS5, MCS9, and MCS13). MCS7 (Fig. 7f) also appears to behave similarly, however the ITF has multiple equatorward surges during this day that complicate our understanding. MCS7 forms on the convergent front associated with the equatorward surge before $12 \mathrm{Z}$ and not the second surge in the early afternoon. MCS4 (Fig. 7d) shows no apparent influence from the ITF, while it is unclear if the northerly flow in close proximity to MCS8 genesis at $17 \mathrm{Z}$ is associated with the ITF or the outflow boundary associated with the MCS generated earlier around 15Z, further north. These results are consistent with other studies of MCSs over West Africa (Taylor et al. 2013; Birch et al. 2014a, b; Maurer et al. 2016) which indicate that Sahel MCSs are more likely to initiate in environments with convergent boundaries, such as those produced by gust fronts or cold pool outflow boundaries.

Another important environmental factor to consider is vertical wind shear. Figure 8 shows the $925-700 \mathrm{hPa}$ storm relative helicity at $12 \mathrm{Z}$ on genesis day. Storm relative helicity is a measure of the potential for cyclonic updraft rotation, and is typically evaluated for the lowest $3 \mathrm{~km}$. All cases, except MCS3 and MCS4, are associated with storm relative helicity values greater than $150 \mathrm{~m}^{2} \mathrm{~s}^{-2}$, which is typically the threshold associated with the development of mid-level rotation and mesocyclones. MCS5 and MCS7 have values greater than $300 \mathrm{~m}^{2} \mathrm{~s}^{-2}$, favorable for strong thunderstorm development. Based on Fig. 3, six of the cases developed into large, well-organized MCSs with maximum areas greater than $50,000 \mathrm{~km}^{2}$. There is strong storm relative helicity for MCS3 at 12Z, but it is west of the genesis location over western Mali and consistent with the 700-hPa mid-level disturbance being over the genesis location instead of farther east upstream (Fig. 4c). Storm relative helicity for MCS4 is relatively weak which is 

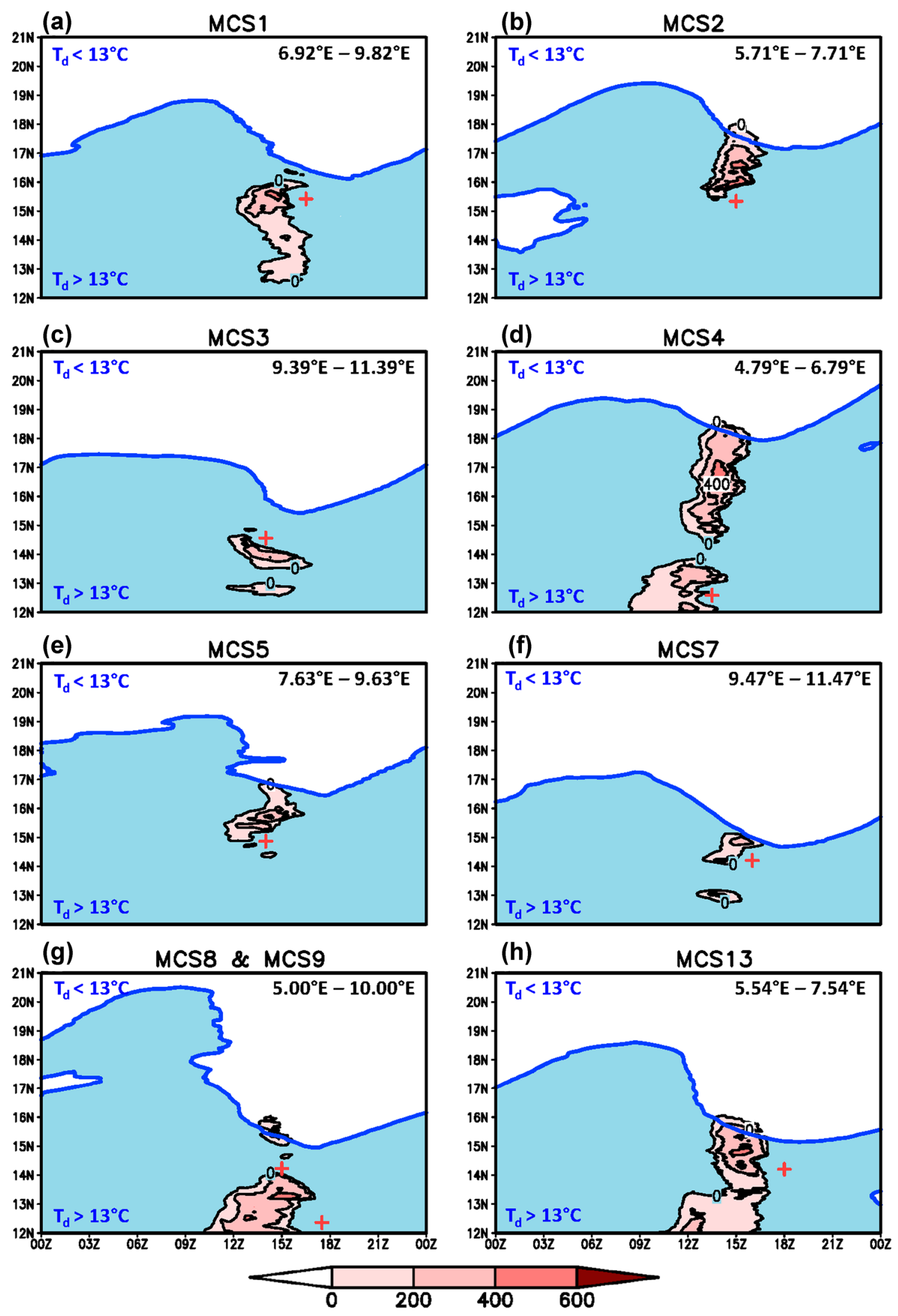
4Fig. 6 Longitudinally averaged time/latitude position of when the PBL height - LFC difference is positive (red shading) on genesis day for a MCS1-3 August 2006, b MCS2-4 August 2006, c MCS3-5 August 2006, d MCS4-7 August 2006, e MCS5-10 August 2006, f MCS7-15 August 2006, g MCS8 and MCS9-18 August 2006, and $\mathbf{h}$ MCS13-28 August 2006. Contour interval is every $200 \mathrm{~m}$. Red crosshairs denote MCS genesis location/time, while the blue lines indicate the time/latitude position of the $925 \mathrm{hPa} 13{ }^{\circ} \mathrm{C}$ isodrosotherm. The longitude bounds used for averaging are provided in each panel

consistent with this event being associated with local processes only.

While Figs. 4 and 7 provide insight into the meridional changes of vertical wind shear, Fig. 9 shows vertical profiles of the diurnal cycle of the zonal wind at $15^{\circ} \mathrm{N}$ averaged between $5^{\circ} \mathrm{E}-10^{\circ} \mathrm{E}$ for the monthly average (Fig. 9a) and the 9 MCS cases (Fig. 9b-i). According to the monthly mean, the zonal component of the flow is westerly below $850 \mathrm{hPa}$ with a nocturnal peak around $6 \mathrm{Z}$ with a magnitude of $7 \mathrm{~m} \mathrm{~s}^{-1}$. At mid-levels, zonal flow is easterly, with a jet at $625 \mathrm{hPa}$ that forms after $21 \mathrm{Z}$ and peaks in magnitude around $9 \mathrm{Z}$ at $12 \mathrm{~m} \mathrm{~s}^{-1}$. The low-level westerly intensification of the flow is associated with the transport of moisture into the drier interior regions of West Africa including Niger (Parker et al. 2005b, Pu and Cook 2010, 2012). The mid-level easterly jet is the AEJ, and is associated with the transport of relatively drier Saharan air into the region (Burpee 1972; Cook 1999).

Strong helicities for MCS1, MCS2, and MCS3 are associated with enhanced low-level zonal westerly flow as the WAWJ intensifies relative to the monthly mean (Fig. 9b-d). Westerly flow is also deeper, extending up to around $750 \mathrm{hPa}$ for MCS1 and MCS2, and $800 \mathrm{hPa}$ for MCS3. At mid-levels, the zonal easterly flow and AEJ are weaker than the monthly mean, and in the case of MCS1 and MCS2, the AEJ is higher up in the atmosphere, near $550 \mathrm{hPa}$.

For the other cases, both the low-level westerly zonal flow and the mid-level easterly zonal flow are weaker for MCS4 (Fig. 9e), consistent with the weak storm relative helicity over the genesis location (Fig. 8d). MCS5 (Fig. 9f) and MCS7 (Fig. 9g) are associated with both a stronger WAWJ and AEJ. In the case of MCS8 and MCS9 (Fig. 9h) the vertical shear is associated with a strong AEJ, as the westerly zonal flow is weak and not as deep (i.e., $~ 875 \mathrm{hPa}$ ). Strong storm relative helicity for MCS13 is associated with both an intensification of the WAWJ and the AEJ, as the AEJ is positioned closer to the surface around $700 \mathrm{hPa}$.

Finally, environmental conditions associated with days without any MCS genesis over the southern Niger Damergou Gap region are analyzed to provide contrast with the above case studies. Seven such days are identified in our simulation. Results from this evaluation (not shown) indicate that days without any MCS genesis over this region are associated with either no $700 \mathrm{hPa}$ southern track disturbance (5 days), or a southern track disturbance to the west of the genesis region with increasing heights in its wake over the genesis region (2 days). Most of the days (6 days) have $12 \mathrm{Z} 925 \mathrm{hPa}$ CAPE values less than the area-averaged $\left(5^{\circ} \mathrm{E}-10^{\circ} \mathrm{E} ; 14^{\circ} \mathrm{N}-16^{\circ} \mathrm{N}\right)$ monthly mean $12 \mathrm{Z}$ value of $1305 \mathrm{~J} \mathrm{~kg}^{-1}$, indicating relatively weak instability. Likewise, 5 of the days have $12 \mathrm{Z} 925-700 \mathrm{hPa}$ storm relative helicity values less than the area-averaged monthly mean $12 \mathrm{Z}$ value of $135 \mathrm{~m}^{2} \mathrm{~s}^{-2}$, indicating relatively weak storm relative helicity/vertical wind shear. Over half of these cases ( 4 days) have the ITF located much farther north between $18^{\circ} \mathrm{N}-20^{\circ} \mathrm{N}$, while the PBL height does not extend above the LFC for 6 of the 7 days.

\subsection{Conditions for MCSs with nighttime genesis $<1000 \mathrm{~km}$ away from analysis region}

Figure 10a, b show the 700-hPa geopotential height anomalies at $00 \mathrm{Z}$ prior to genesis for the two nighttime genesis cases. MCS10 and MCS14 are both associated with disturbances in the southerly and northerly disturbance tracks. In the case of MCS10, there is a strong disturbance centered at $20^{\circ} \mathrm{N}$ and $5^{\circ} \mathrm{E}$ to the north-northwest of the genesis location, as well as a disturbance centered at $10^{\circ} \mathrm{N}$ and $15^{\circ} \mathrm{E}$ to the southeast of the genesis area. The disturbance in the northern track leads the southern track disturbance by about $10^{\circ}$ of longitude, and is closer to the genesis area. This suggests that the northern disturbance is having a greater impact on the MCS genesis by enhancing the lowlevel westerly zonal flow and, hence, the low-level moisture supply over western Niger (not shown). Unlike the Sect. 4a cases, MCS10 forms along a low-level gust/front convergence boundary that is associated with convection earlier in the evening over the Air Mountains to the north of the genesis region.

MCS14 has a similar synoptic pattern with a disturbance centered at $22^{\circ} \mathrm{N}$ and $12^{\circ} \mathrm{E}$ in the northern disturbance track, and a second disturbance centered at $11^{\circ} \mathrm{N}$ and $12^{\circ} \mathrm{E}$ in the southern disturbance track. However, these two disturbances are aligned longitudinally, with the northern disturbance weaker compared to MCS10. For this case the genesis location is closer to the southern disturbance. There is still enhanced low-level westerly zonal flow and moisture transport into the genesis area, but it is weaker relative to MCS10 (not shown). MCS14 also forms along a low-level convergence outflow boundary. In this case, the boundary is associated with afternoon/evening convection over western Chad.

Figure 10c, d show CAPE at $00 \mathrm{Z}$ on genesis day for MCS10 and MCS14. Atmospheric instability directly over the genesis location is weak (less than $1200 \mathrm{~J} \mathrm{~kg}^{-1}$ ) for both cases. However, there is moderate instability 

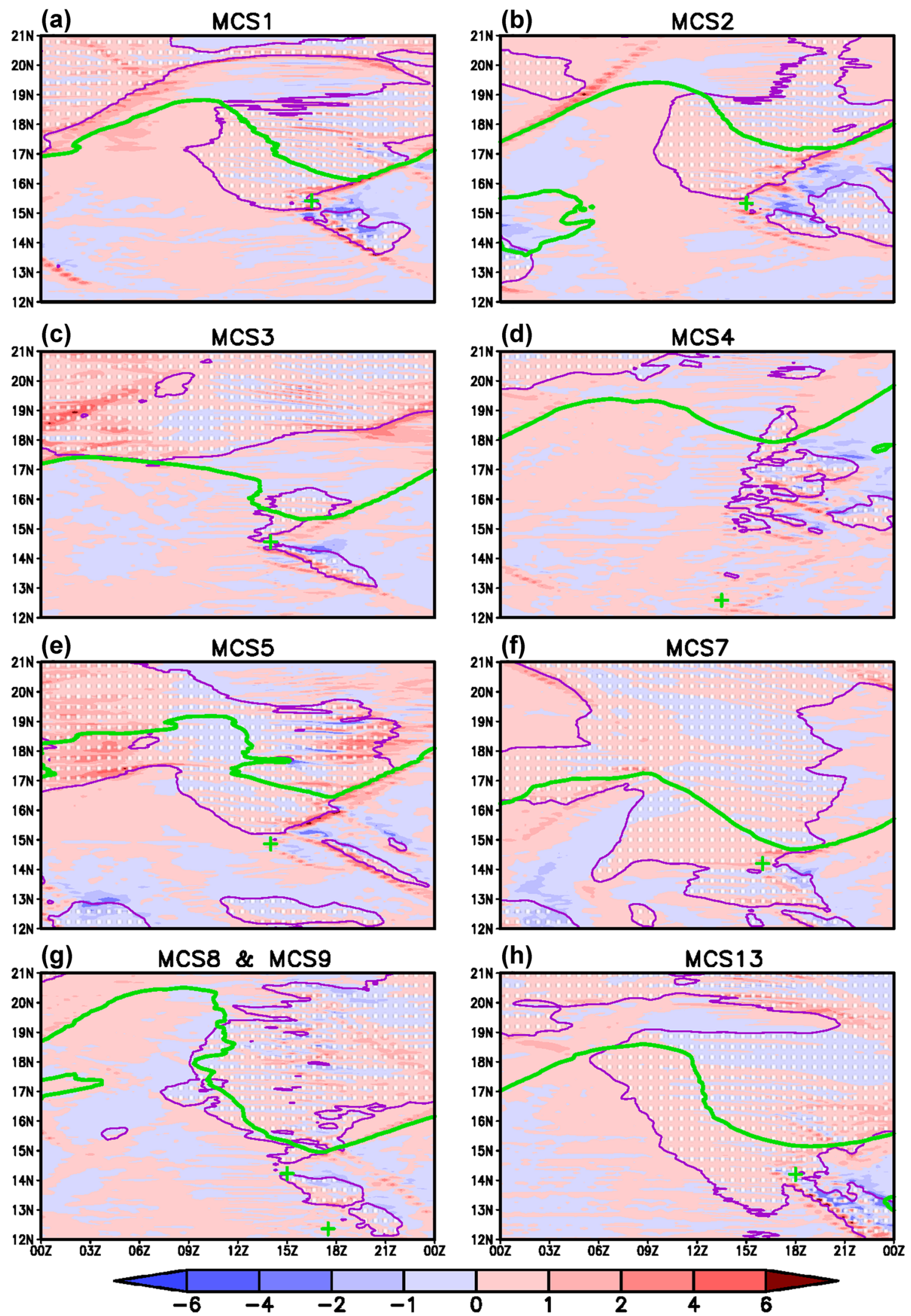
4Fig. 7 Diurnal cycle of the longitudinally averaged $925 \mathrm{hPa}$ wind convergence $\left(\times 10^{-4} \mathrm{~s}^{-1}\right.$; shading), location of the $925 \mathrm{hPa} 0 \mathrm{~m} \mathrm{~s}^{-1}$ meridional component of the wind (purple line), and location of the $925 \mathrm{hPa} 13{ }^{\circ} \mathrm{C}$ isodrosotherm (green line) on genesis day for a MCS1-3 August 2006, b MCS2-4 August 2006, c MCS3-5 August 2006, d MCS4-7 August 2006, e MCS5-10 August 2006, f MCS7-15 August 2006, g MCS8 and MCS9-18 August 2006, and h MCS13-28 August 2006. Green crosshairs denote MCS genesis location/time, while stippling denotes where/when meridional component of the wind is northerly. Longitude bounds used for averaging are the same as Fig. 6

(CAPE $>1200 \mathrm{~J} \mathrm{~kg}^{-1}$ ) relatively close by for MCS10. For MCS14, the instability is weak over northern Nigeria downstream of the genesis location.

Figure $10 \mathrm{e}$, $\mathrm{f}$ show the $925-700 \mathrm{hPa}$ storm relative helicity at $00 \mathrm{Z}$ on genesis day for each case. MCS10 originates in an environment with moderate to strong storm relative helicity $\left(150-300 \mathrm{~m}^{2} \mathrm{~s}^{-1}\right)$ associated with a stronger and deeper (to $775 \mathrm{hPa}$ ) westerly/southwesterly low-level inflow on the southern flank of the northern track disturbance (Fig. 10a). The WAWJ peaks during the early morning hours (not shown), and is 30-40\% stronger than the monthly average (Fig. 9a). MCS14 storm relative helicity is weaker in the genesis region, generally less than $150 \mathrm{~m}^{2}$ $\mathrm{s}^{-2}$. However, further downstream near the analysis region storm relative helicity is much more favorable for the development of mid-level rotation.

Figure $10 \mathrm{~g}$, h show the diurnal cycle of the $925-\mathrm{hPa}$ meridional wind and the $13{ }^{\circ} \mathrm{C}$ isodrosotherm averaged between $5^{\circ} \mathrm{E}-10^{\circ} \mathrm{E}$ for $\mathrm{MCS} 10$ and MCS14, respectively. The genesis and development of MCS10 is not associated with the ITF, which is located farther north between $18^{\circ} \mathrm{N}-20^{\circ} \mathrm{N}$ on this day, and the low-level meridional component of the flow remains southerly throughout the day south of $17^{\circ} \mathrm{N}$.

For MCS14, while the ITF is near its average location between $16^{\circ} \mathrm{N}$ and $18^{\circ} \mathrm{N}$, there is little evidence of an afternoon reversal to northerly flow on its poleward side. South of $16.5^{\circ} \mathrm{N}$, low-level flow changes from southerly to northerly between $12 \mathrm{Z}$ and $21 \mathrm{Z}$, but this reversal is more likely associated with the developing MCS circulation and not the ITF itself. Given the close proximity of the frontal boundary in the afternoon, it appears that MCS14 is drawing drier Sahel/Saharan air into the developing system.

\subsection{Conditions for MCSs with genesis $>1000 \mathrm{~km}$ away from analysis region}

Figure 11 shows 700-hPa geopotential height anomalies for each event that forms more than $1000 \mathrm{~km}$ from the analysis region. MCS6 (Fig. 11a) and MCS11 (Fig. 11b) originate at night, while the remaining three cases originate during the day (Fig. 11c-e). Mid-tropospheric disturbances play an important role for all of the cases, with MCS6, MCS15, and MCS16 primarily associated with a disturbance in the southern disturbance track in the vicinity of the genesis location, while MCS11 and MCS12 are associated with disturbances in both the northern and southern disturbance tracks, with the northern disturbance leading the southern disturbance.

Figure 12 shows the diurnal cycle of the 925-hPa meridional wind component along with the latitudinal location of the $13{ }^{\circ} \mathrm{C}$ isodrosotherm on genesis day for the $5 \mathrm{MCS}$ cases. Based on the results from Fig. 12, the generation of MCS6, MCS11, MCS15, and MCS16 is not directly associated with the ITF as genesis occurs well south of the ITF boundary, near or south of $12^{\circ} \mathrm{N}$ where the low-level meridional flow is southerly throughout the day. Additionally, there is no evidence that the ITF influenced any of the subsequent MCS intensification peaks (Fig. 3) for these cases (not shown). Instead, MCS11, MCS15, and MCS16 are primarily synoptically-forced by the African easterly wave disturbance in the southern disturbance track around $10^{\circ} \mathrm{N}$, while MCS6 forms at night along a low-level convergence boundary associated with convective activity over the Ethiopian Plateau earlier in the evening.

MCS12 (Fig. 12c), however, is associated with the ITF. The low-level meridional flow field between $12^{\circ} \mathrm{N}$ and $16^{\circ} \mathrm{N}$ for this case exhibits the diurnal oscillation of the meridional flow associated with the ITF (Fig. 6), and the MCS forms at the low-level convergence frontal boundary around 18Z. Furthermore, the ITF also appears to be associated with MCS12's intensification during the second day of its existence by helping to increase the afternoon lowlevel wind convergence in close proximity to the developing MCS.

\subsection{MCS relationship with African easterly waves}

Figure 13 shows Hovmöller diagrams of $700-\mathrm{hPa}$ geopotential height anomalies averaged between $8^{\circ} \mathrm{N}-15^{\circ} \mathrm{N}$ for the southern disturbance track (Fig. 13a), and between $16^{\circ} \mathrm{N}-20^{\circ} \mathrm{N}$ for the northern disturbance track (Fig. 13b) from the model simulation. Dashed lines indicate westward propagating disturbances with estimated zonal phase speeds noted for each.

For the southern disturbance track, east of $5^{\circ} \mathrm{W}$, nine disturbances are identified in the simulation with estimated zonal phase speeds ranging from 5 to $20 \mathrm{~m} \mathrm{~s}^{-1}$. Most of these disturbances have zonal phase speeds typically of 3-5 day AEW disturbances (Burpee 1972; Reed et al. 1977; Diedhiou et al. 1999; Hsieh and Cook 2005). MCS genesis occurs either ahead of (to the west) or coincidental with the disturbance, consistent with previous studies (Burpee 1972; Duvel 1989; Diedhiou et al. 1999; Fink et al. 2006; Crétat et al. 2014). Two cases, MCS4 

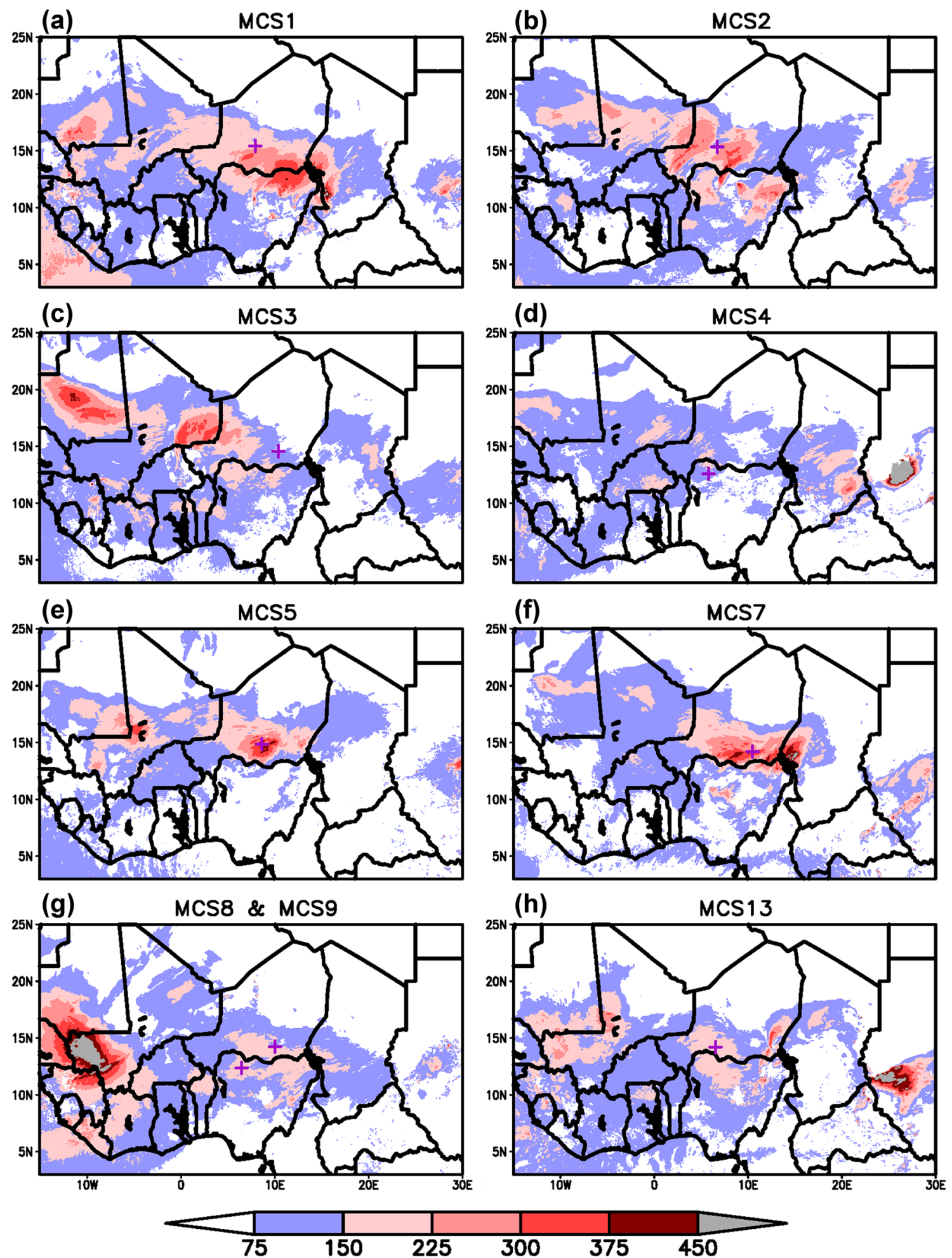

Fig. 8 925-700 hPa storm relative helicity $\left(\mathrm{m}^{2} \mathrm{~s}^{-2}\right)$ at $12 \mathrm{Z}$ on genesis day for the cases a MCS1, b MCS2, c MCS3, d MCS4, e MCS5, f MCS6, g MCS8 and MCS9, and $\mathbf{h}$ MCS13. Crosshairs denote MCS genesis location

and MCS12, have no apparent relationship to westward propagating southern track disturbances. As discussed earlier, the former is not associated with any mid-level disturbance (Fig. 4d), while the latter is associated more closely with a disturbance in the northern track (Fig. 11c).

For the northern disturbance track, 7 disturbances are identified. Zonal phase speeds range from 5 to $30 \mathrm{~m} \mathrm{~s}^{-1}$, 

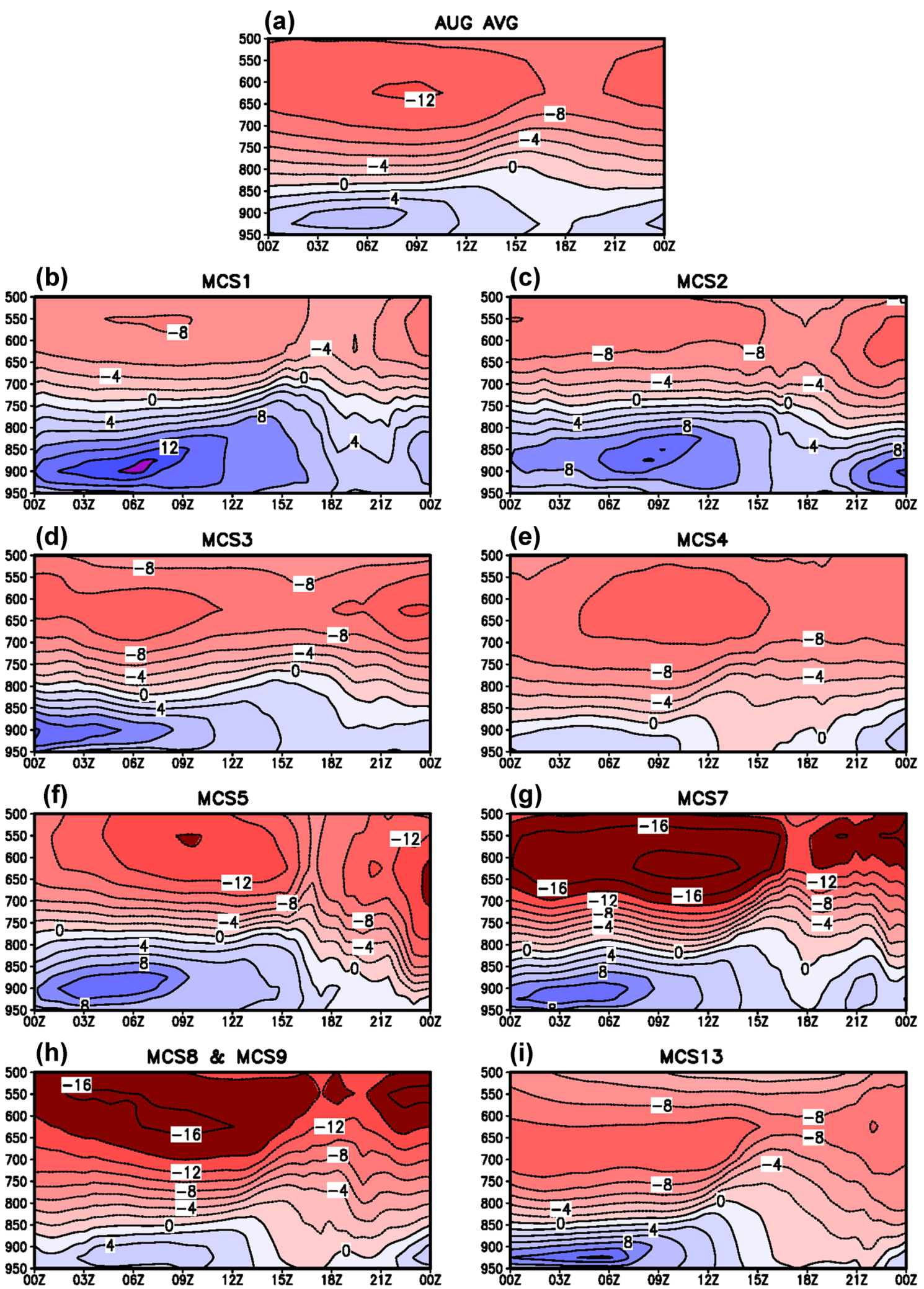

Fig. 9 Vertical profiles of the simulated diurnal cycle of the zonal wind $\left(\mathrm{m} \mathrm{s}^{-1}\right)$ at $15^{\circ} \mathrm{N}$ averaged between $5^{\circ} \mathrm{E}$ and $10^{\circ} \mathrm{E}$ over Niger for a the August 2006 average, b MCS1-3 August 2006, c MCS2-4 August 2006, d MCS3-5 August 2006, e MCS4-7 August 2006,

f MCS5-10 August 2006, g MCS7-15 August 2006, h MCS8 and MCS9-18 August 2006, and i MCS13-28 August 2006. Contours are drawn every $2 \mathrm{~m} \mathrm{~s}^{-1}$, while blue (red) shading denotes westerly (easterly) flow 
(a) MCS10: $700 \mathrm{hPa}$ HGT anom.

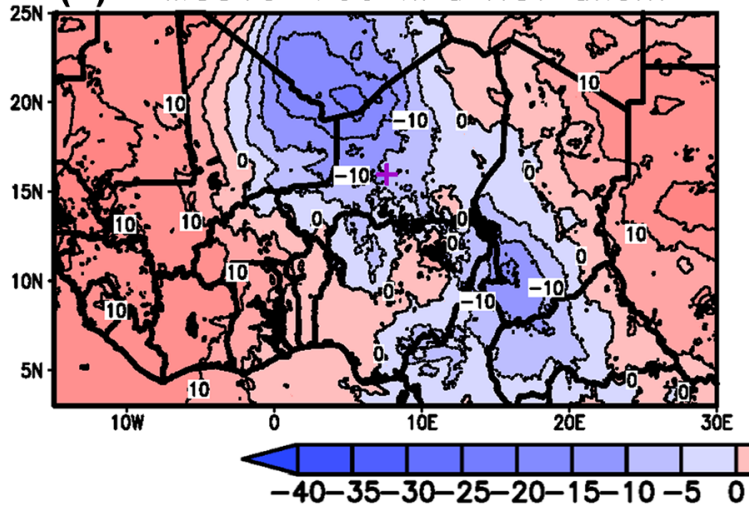

(c)

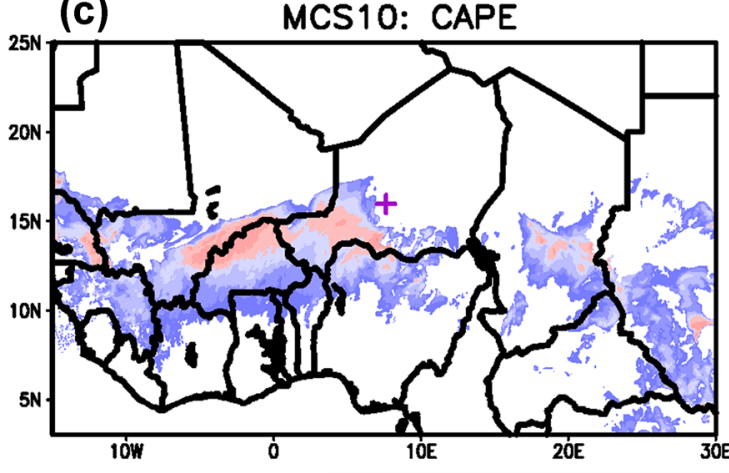

(b) MCS14: $700 \mathrm{hPa}$ HGT anom.

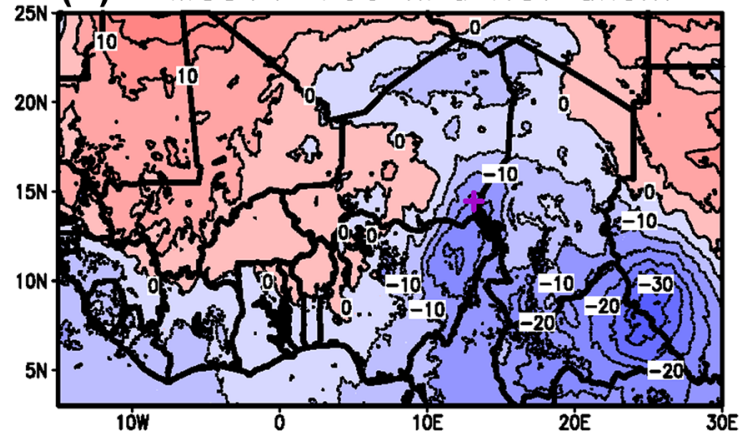

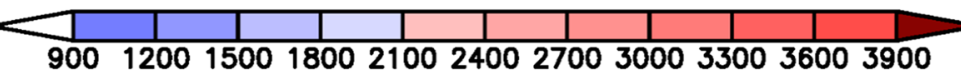

(e) MCS10: Helicity

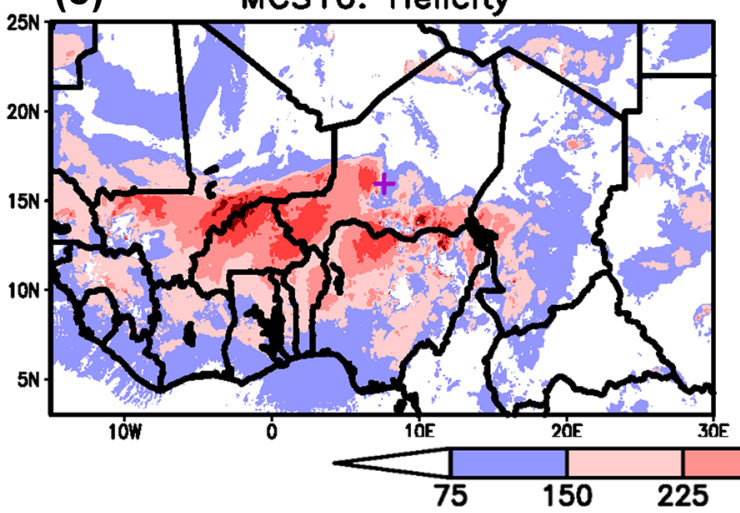

(g)

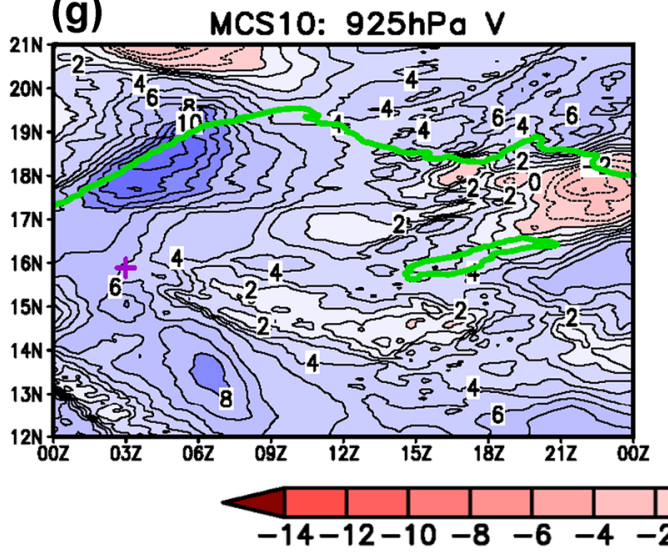

(f)

(d) MCS14: CAPE

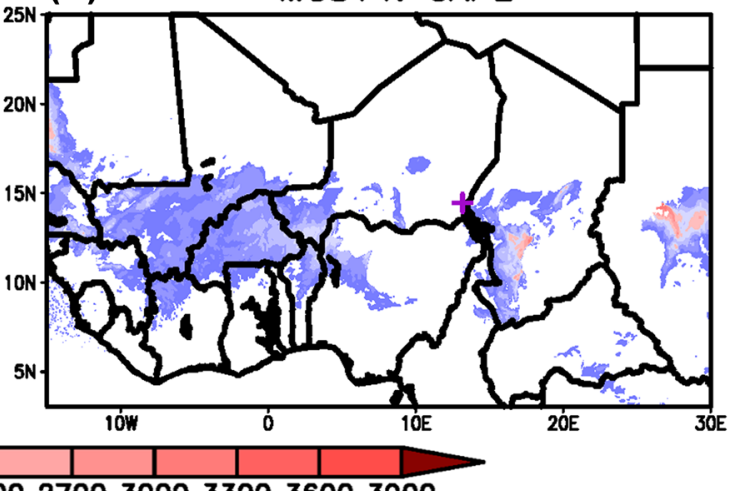

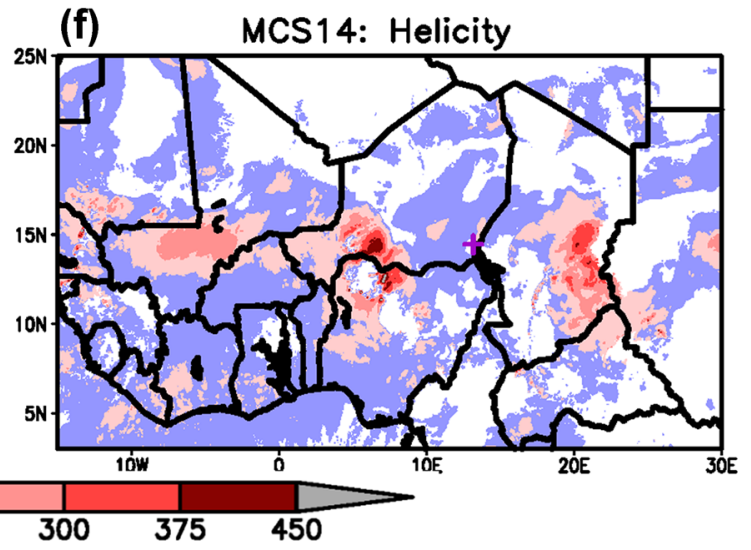

(h) MCS14: $925 \mathrm{hPa} \mathrm{V}$

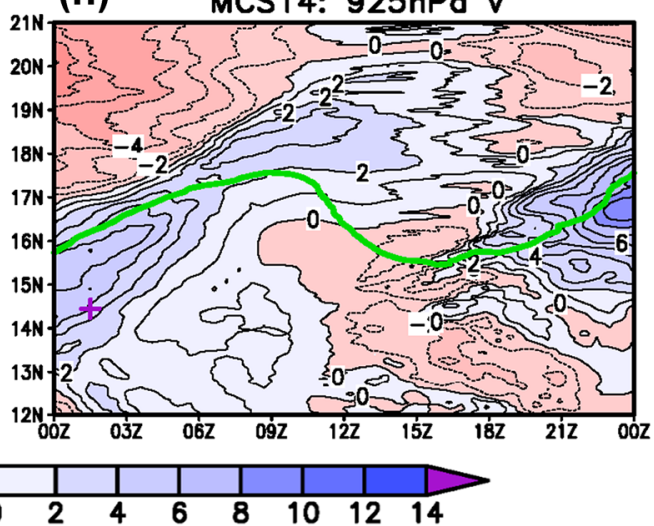


4Fig. $1000 \mathrm{Z}$ on MCS genesis day for a MCS10 and b MCS14 $700 \mathrm{hPa}$ geopotential height anomalies (m), c MCS10 and d MCS14 $925 \mathrm{hPa}$ CAPE $\left(\mathrm{J} \mathrm{kg}^{-1}\right)$, and e MCS10 and f MCS14 925-700 hPa storm relative helicity $\left(\mathrm{m}^{2} \mathrm{~s}^{-2}\right)$. $\mathbf{g}$ MCS10 and $\mathbf{h}$ MCS14 diurnal cycle of the meridional wind component $\left(\mathrm{m} \mathrm{s}^{-1}\right)$ and $13{ }^{\circ} \mathrm{C}$ isodrosotherm (green line) averaged between $5^{\circ} \mathrm{E}-10^{\circ} \mathrm{E}$. Crosshairs denote MCS genesis location

but with only one disturbance slower than $11 \mathrm{~m} \mathrm{~s}^{-1}$. That slower disturbance has a zonal phase speed typically associated with 6-9 day AEWs (Diedhiou et al. 1999; Wu et al. 2013). The rest of the disturbances have phase speeds faster than AEWs, but are similar to the estimated phase speeds of organized convection observed over northern Africa (Fink et al. 2006; Laing et al. 2008). 6 of the 16 MCSs (i.e., MCS4, MCS6, MCS7, MCS8, MCS9, and MCS13) are not associated with a northern-track disturbance, while the remaining 10 MCSs are with the disturbance either north or northwest of the MCS genesis location, consistent with Burpee (1972) and Duvel (1989). Similar results are obtained if $850 \mathrm{hPa}$ geopotential height anomalies averaged for the northern disturbance track are analyzed instead, as $850 \mathrm{hPa}$ is more commonly used to identify northern track AEWs.

Figure 13c, d show the same analysis using the ERAI reanalysis with the CMORPH MCS genesis positions overlain. Overall, the simulation reasonably simulates AEWs in both tracks compared to ERAI. The most noticeable difference is that wave disturbances in the model tend to have slower propagation speeds compared to ERAI in all cases. The relationship between the wave disturbances and the MCS genesis also appear to be relatively similar.

The results above confirm that AEW disturbances are an important catalyst for MCS genesis and development over the Sahel. In the model simulation analyzed, only MCS4 is not associated with a disturbance in either track, as this event was locally-forced by daytime heating instead of being synoptically forced.

\subsection{Relationship between MCSs and rainfall}

Figure 14a shows the time series of rainfall area-averaged over the analysis region (Fig. 1) for the model simulation, while Fig. 14b shows a similar time series for CMORPH. The time series is color-coded based on the time of day and how far from the analysis region MCS genesis occurs. The simulated rainfall amounts are in reasonable agreement with CMORPH, except rainfall associated with nighttime MCS genesis $<1000 \mathrm{~km}$ away is larger in the model. Additionally, the rainfall not associated with MCS activity (black lines) is greater in the model.

A breakdown of the percentage of rainfall in the analysis region associated with MCSs of different origins is provided in Table 1 . In the model, $82 \%$ of the total rainfall is associated with MCSs, while this percentage is $90 \%$ for CMORPH. This difference is associated with having more unclassified rainfall events in the model, suggesting that isolated/localized convection is larger than in the observations. The simulated analysis region precipitation associated with MCS genesis $<1000 \mathrm{~km}$ away (65\%) also agrees with the observations $(70 \%)$, but the partitioning between daytime and nighttime genesis events differs, as the simulation indicates a greater contribution for nighttime MCS genesis events. Given the small number of cases, it is unclear whether this is a systematic problem in the model. Finally, the percentage of total rainfall associated with MCSs that originate $>1000 \mathrm{~km}$ away is around $20 \%$ in both the simulation and CMORPH.

Figure 14c, d show a breakdown of the August 2006 diurnal cycle of analysis region rainfall for the model and CMORPH, while Fig. 14e, f show the quantification of this breakdown expressed as percentages relative to the total rainfall at each time. For the model, the largest rainfall maximum $\left(\sim 21 \mathrm{~mm}\right.$ day $\left.^{-1}\right)$ occurs overnight between $21 \mathrm{Z}$ and $00 \mathrm{Z}$ with over $90 \%$ of this rainfall associated with MCS activity. This agrees with CMORPH, except that the maximum is lower $\left(\sim 13 \mathrm{~mm} \mathrm{day}{ }^{-1}\right)$. Daytime MCS genesis $<1000 \mathrm{~km}$ away from the analysis region accounts for approximately $80 \%$ of the nocturnal rainfall in the model, but this percentage is a little lower in CMORPH between $19 \mathrm{Z}$ and $23 \mathrm{Z}(\sim 60 \%)$ as MCSs with genesis $>1000 \mathrm{~km}$ away are more influential during this time. This suggests that the model may not be properly simulating the development of these long-lived systems. The possible explanations for this discrepancy are many, including slower moving AEW disturbances (Fig. 13), and warrants further attention in the future. Overall, the model and observations agree that the nocturnal rainfall in this region is primarily associated with MCSs that originate in the afternoon to the north and east relatively close by (within $1000 \mathrm{~km}$ ).

A secondary rainfall maximum $\left(\sim 12 \mathrm{~mm} \mathrm{day}^{-1}\right)$ occurs between $15 \mathrm{Z}-18 \mathrm{Z}$ in the model simulation, but during this time a smaller percentage $(50-75 \%)$ of the total rainfall is associated with MCS activity. For this maximum, the contributions from the MCSs of different origins and/or genesis time are more equal among the three different kinds of events. CMORPH does not indicate a secondary afternoon rainfall maximum, but the TRMM 3B42V7 rainfall product suggests that one may exist, just with lower rainfall rates than in the model simulation (not shown).

Likewise, there is not good agreement between the model and CMORPH for rainfall activity between $6 \mathrm{Z}-12 \mathrm{Z}$. At this time there is little contribution from daytime MCS genesis within $1000 \mathrm{~km}$ in the model, while CMORPH indicates that it is most important. This discrepancy is likely associated with the fact that these 

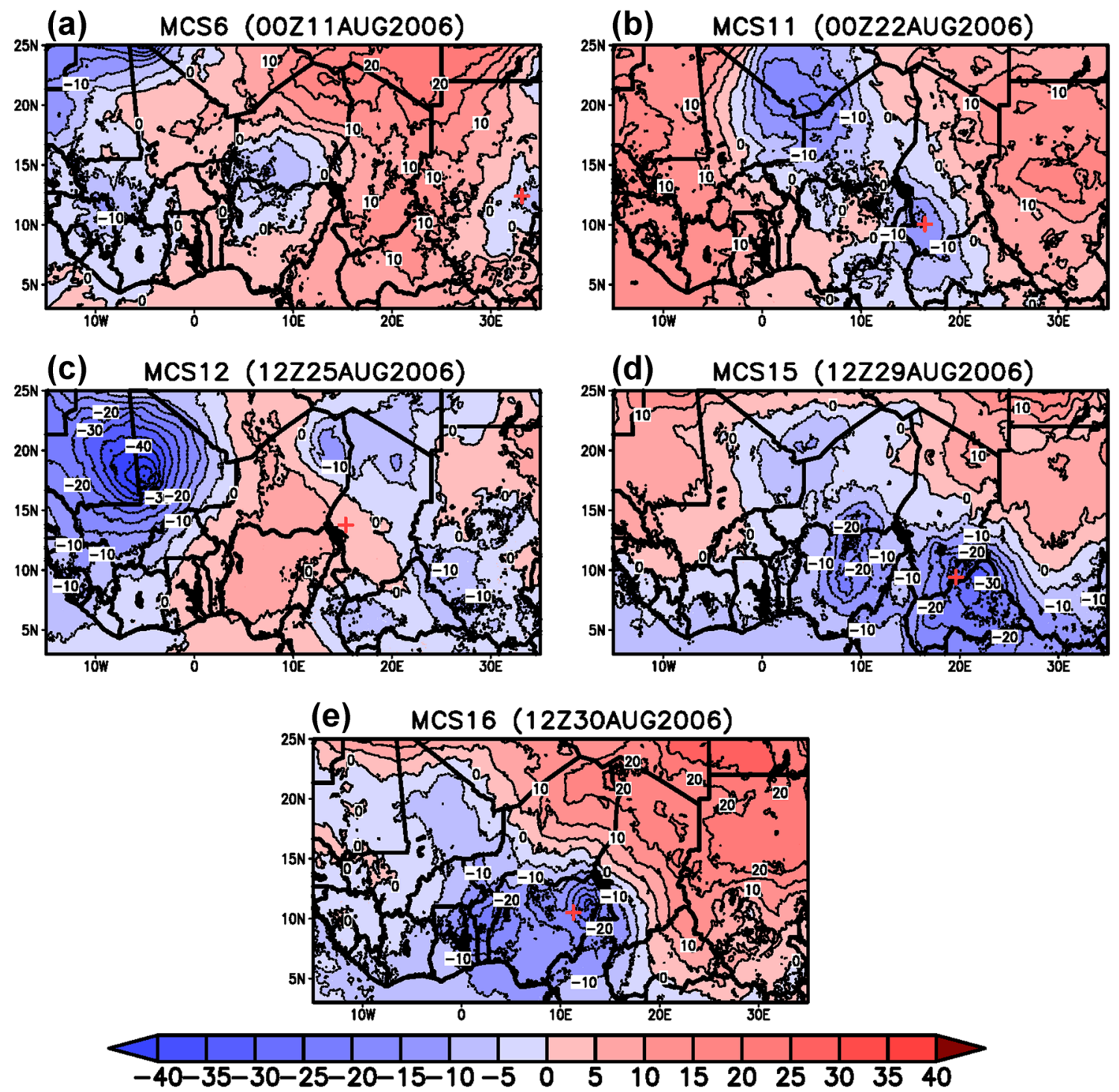

Fig. $11700 \mathrm{hPa}$ geopotential height anomalies (m) prior to genesis for a MCS6, b MCS11, c MCS12, d MCS15, and e MCS16. Time of each case is denoted in panel label. Crosshairs denote MCS genesis location

MCSs are shorter lived by about $8 \mathrm{~h}$ on average in the model than in CMORPH.

Of interest are two times when rainfall activity not associated with MCSs is found to be more influential. They are at dawn, around 06Z, and during the afternoon between 14Z and 19Z. Physically, this makes sense as the afternoon is when local convection occurs, and the rainfall systems are becoming organized. Likewise, around $06 \mathrm{Z}$ is when the organized rainfall systems have weakened and are typically breaking up. In both instances, the size criterion for MCSs may not be met, accounting for the lower percentages.

\subsection{Application of results for the entire southwestern Sahel}

The applicability of these findings outside the small analysis region is evaluated. Based on this and other studies (Laurent et al. 1998; Laing et al. 1999; Mathon et al. 2002; Mohr 2004) that demonstrate a high percentage of rainfall over the Sahel is due to MCSs, we can examine the diurnal cycle of rainfall for other southwestern Sahel regions to identify nocturnal peaks in rainfall in the model simulation and CMORPH, then see if this maximum is preceded by afternoon rainfall upstream to the north and east. Where 

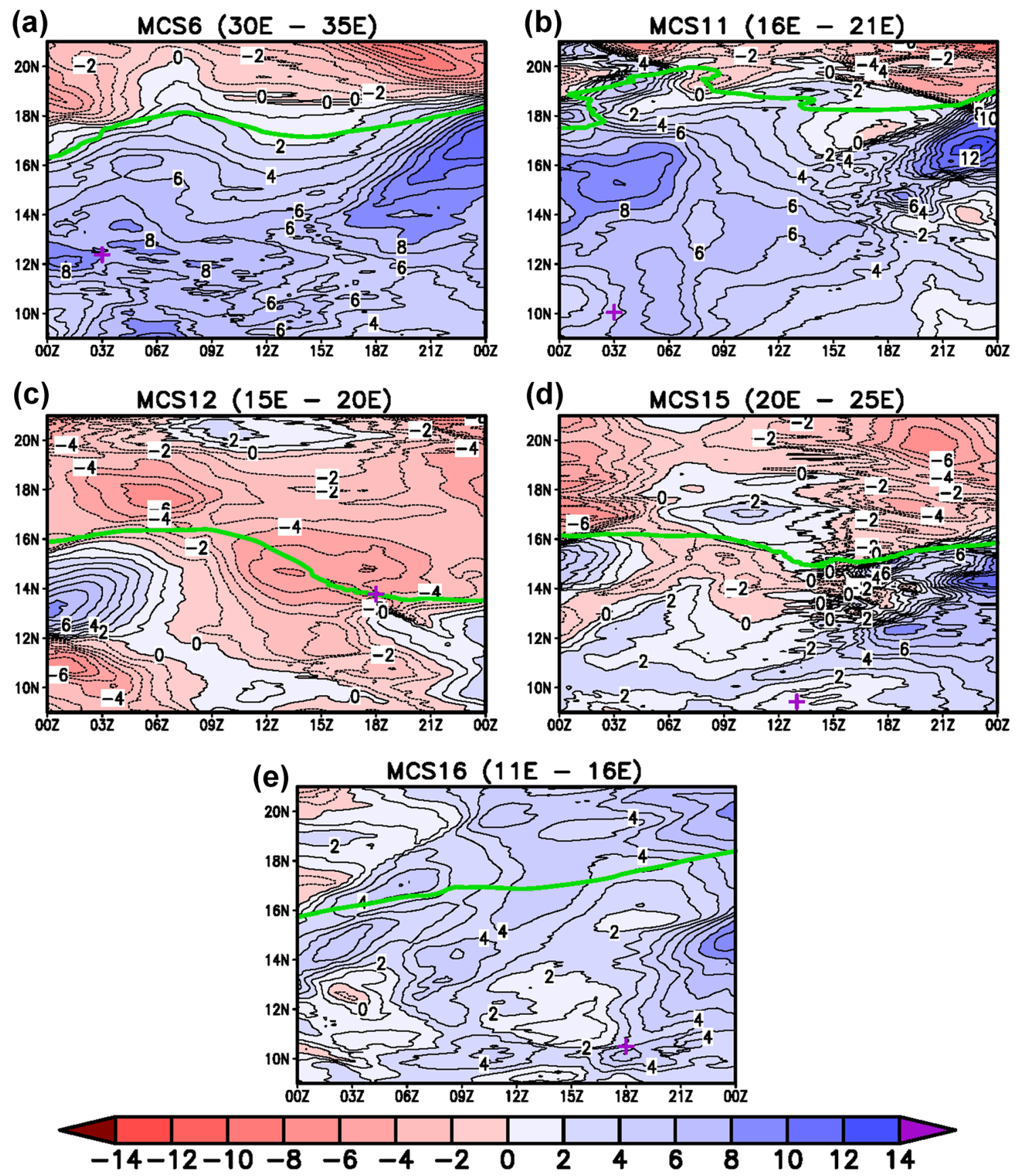

Fig. 12 Simulated diurnal cycle of the $925 \mathrm{hPa}$ meridional wind component $\left(\mathrm{m} \mathrm{s}^{-1}\right)$ and $13{ }^{\circ} \mathrm{C}$ isodrosotherm (green line) for a MCS6-11 August 2006 averaged between $30^{\circ} \mathrm{E}-35^{\circ} \mathrm{E}$, b MCS11-22 August 2006 averaged between $16^{\circ} \mathrm{E}-21^{\circ} \mathrm{E}$, c MCS12-25 August

this is the case, we can imply that the ITF mechanism discussed here is operating.

Three averaging regions are evaluated and shown in Fig. 15a. They include R1, which is our original averaging region, $\mathrm{R} 2$ which is centered over western Senegal, and R3 over southern Mali. The regions are selected $6^{\circ}-8^{\circ}$ of
2006 averaged between $15^{\circ} \mathrm{E}-20^{\circ} \mathrm{E}, \mathbf{d}$ MCS4-29 August 2006 averaged between $20^{\circ} \mathrm{E}-25^{\circ} \mathrm{E}$, and e MCS16-30 August 2006 averaged between $11^{\circ} \mathrm{E}-16^{\circ} \mathrm{E}$. Crosshairs denote time and latitudinal position of MCS genesis for each event

longitude apart to sub-sample the entire southwestern Sahel and minimize potential overlap among the analysis regions.

R1, R2, and R3 (Fig. 15b-d) behave in a similar manner for the model simulation and CMORPH observations. In particular, there is a late afternoon peak in rainfall upstream in the simulation and observations around $18 \mathrm{Z}$ 

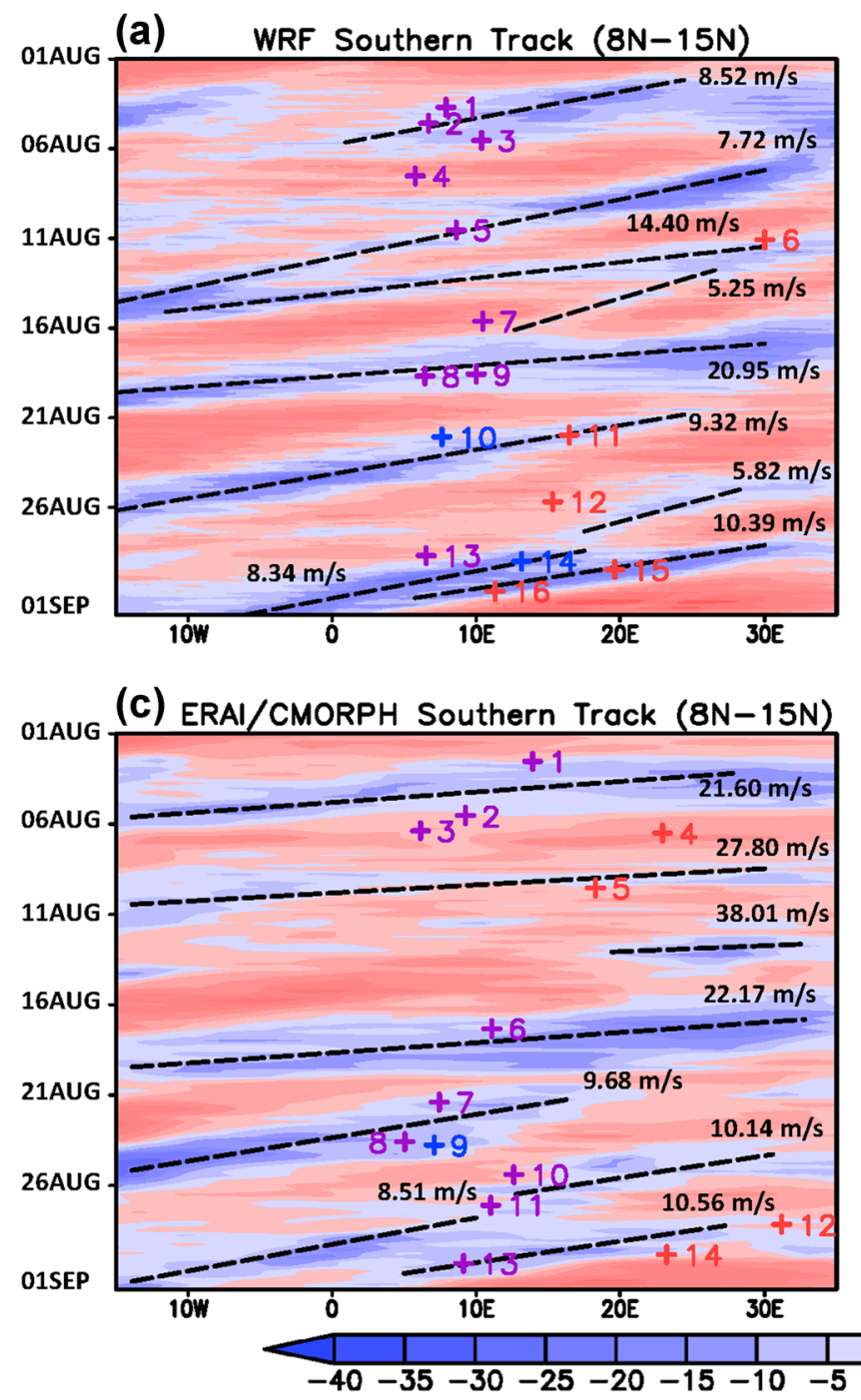

Fig. 13 WRF $700 \mathrm{hPa}$ geopotential height anomalies (m) for the a southern disturbance track averaged between $8^{\circ} \mathrm{N}-15^{\circ} \mathrm{N}$, and $\mathbf{b}$ northern disturbance track averaged between $16^{\circ} \mathrm{N}-20^{\circ} \mathrm{N}$. Dashed lines denote $700 \mathrm{hPa}$ disturbances in each track. Estimated zonal phase speed $\left(\mathrm{m} \mathrm{s}^{-1}\right)$ for each disturbance is provided. Cross hairs denote

(dashed lines) followed by a peak in rainfall in the downstream averaging box at 20-23Z (solid lines).

$925 \mathrm{hPa}$ low-level wind convergence is also evaluated for the three regions from the model simulation (Fig. 15e-g). While there are some differences among the profiles from the different regions, they all indicate that the low-level wind convergence is strongest during the daytime for the upstream areas between $14^{\circ} \mathrm{N}-16^{\circ} \mathrm{N}$, but farther south between $12^{\circ} \mathrm{N}-14^{\circ} \mathrm{N}$, wind convergence is strongest after 18Z. Furthermore, the strong daytime low-level wind convergence upstream typically begins in the morning and lasts for multiple hours prior to rainfall, consistent with past studies (Taylor et al. 2013; Birch et al. 2014a, b; Maurer et al. 2016).

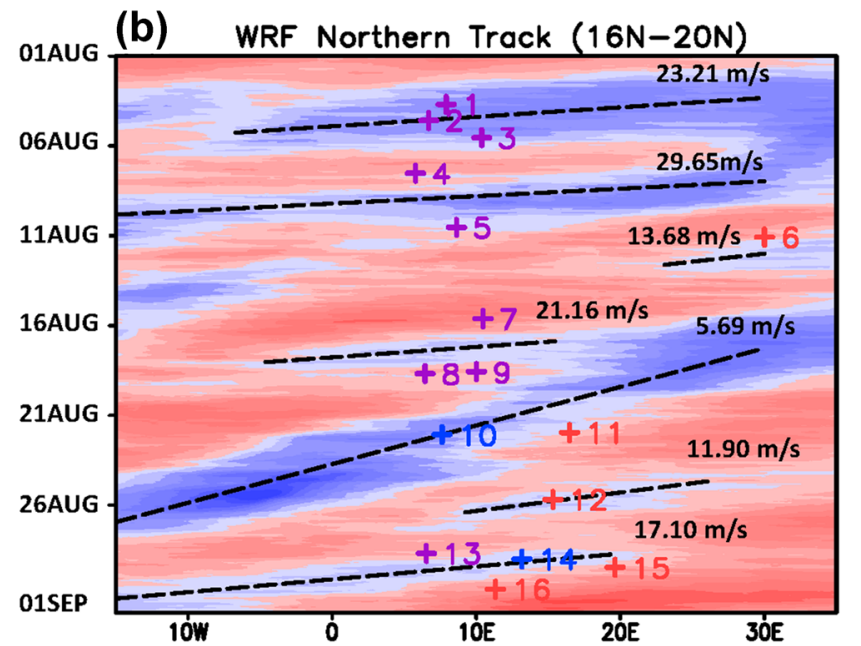

(d) ERAI/CMORPH Northern Track (16N-20N)

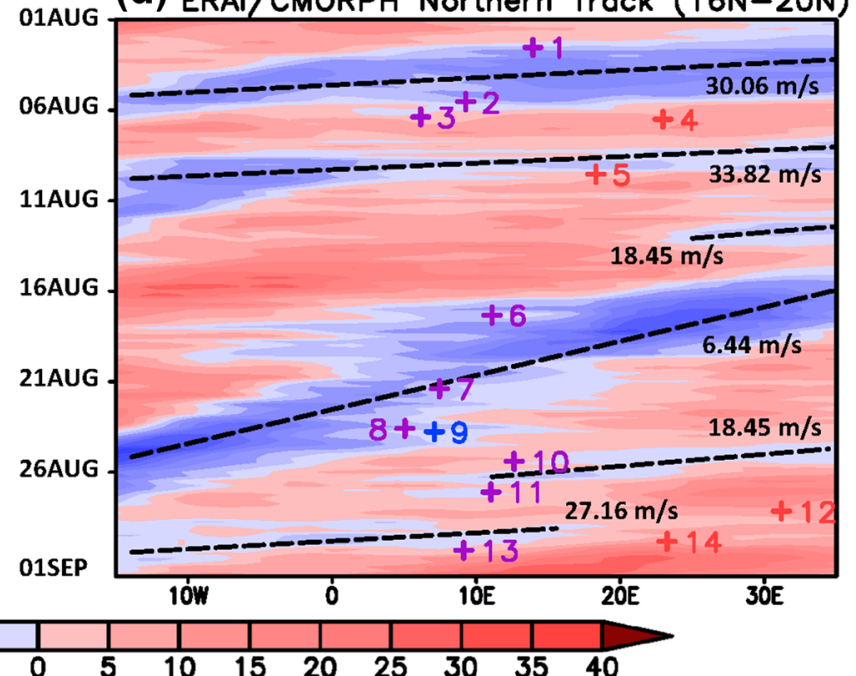

the genesis longitude and time for the (purple) daytime MCS genesis $<1000 \mathrm{~km}$ away, (blue) nighttime MCS genesis $<1000 \mathrm{~km}$ away, and (red) MCS genesis $>1000 \mathrm{~km}$ away. $\mathbf{c}$ and $\mathbf{d}$ are the same as $\mathbf{a}$ and $\mathbf{b}$, respectively, except from ERAI and CMORPH

Based on the analysis from Fig. 15, we conclude that the findings for the small analysis region apply to the southwestern Sahel, and that the ITF is playing an influential role in MCS development across the region.

\section{Conclusions}

A convection-permitting regional model simulation and observational data are used to understand why there is a nocturnal rainfall maximum over the southwestern Sahel during the height of West African monsoon in August 2006, and how this nighttime rainfall maximum relates to MCS activity and the Sahel ITF. A 1-month triple-nested 

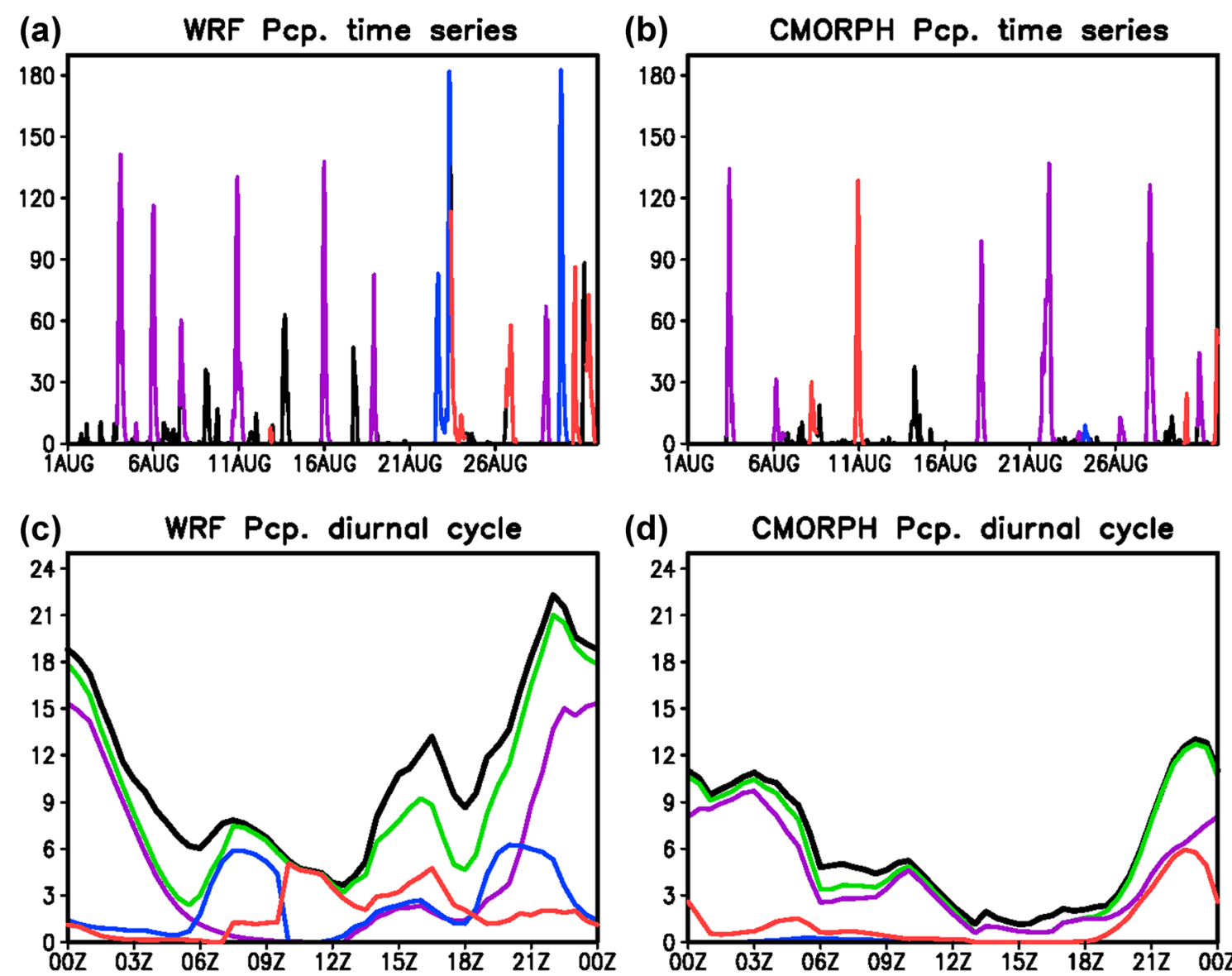

(d) CMORPH Pcp. diurnal cycle
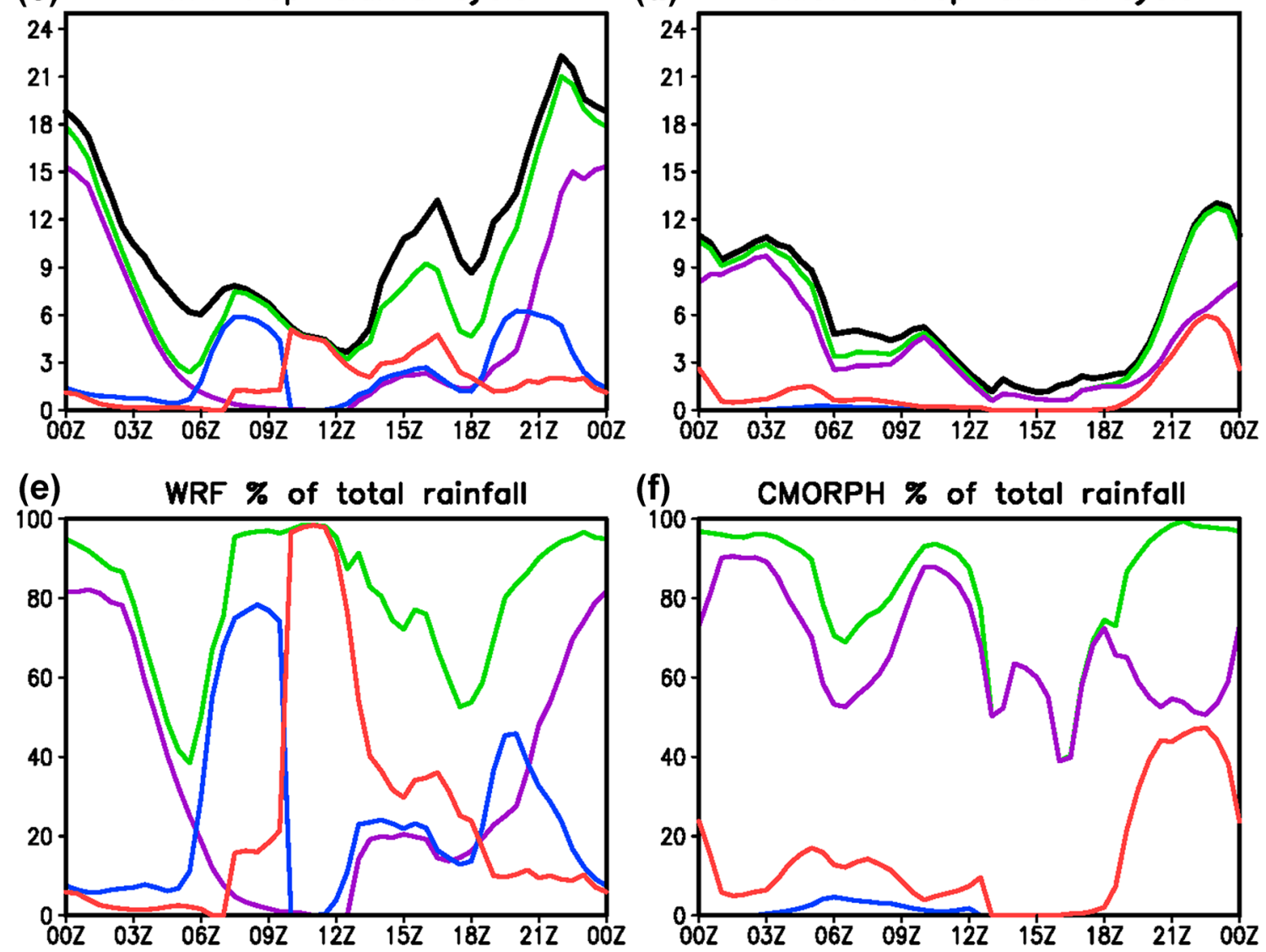

(f)

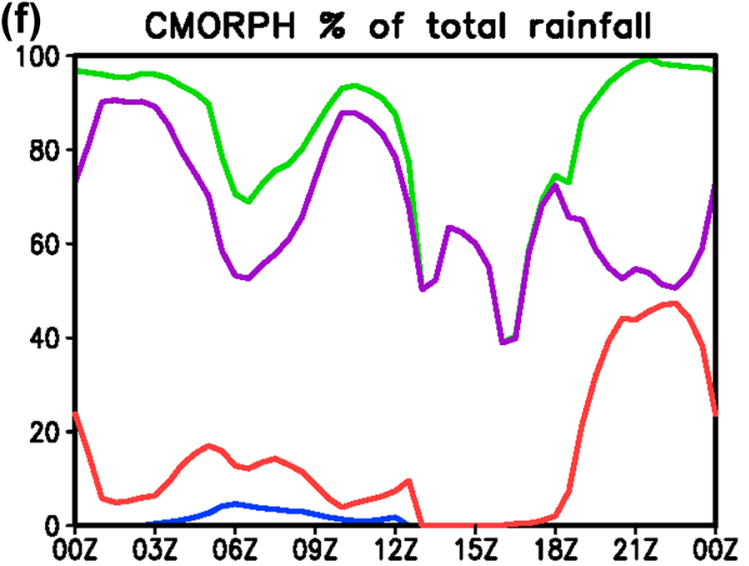

Fig. 14 Time series of the August 2006 rainfall $(\mathrm{mm})$ area-averaged for the analysis region from a WRF and $\mathbf{b}$ CMORPH. Additionally, August 2006 diurnal cycle of precipitation (mm/day) for the analysis region from c WRF and d CMORPH, including a breakdown by MCS classification types. e WRF and $\mathbf{f}$ CMORPH percentage of total precipitation associated with MCSs and the different MCS clas-

sification types. In all panels black denotes total precipitation, while purple, blue, and red denote daytime MCS genesis $<1000 \mathrm{~km}$ away, nighttime MCS genesis $<1000 \mathrm{~km}$ away, and MCS genesis $>1000 \mathrm{~km}$ away, respectively. The green lines in $\mathbf{c}-\mathbf{f}$ denotes the sum of all MCSs

$27-\mathrm{km} / 9-\mathrm{km} / 3-\mathrm{km}$ simulation with one-way nesting is employed. Lateral boundary conditions for the $27-\mathrm{km}$ domain are derived from the ERAI reanalysis, while the 9- and 3-km domain lateral boundary conditions

are derived from the solutions of the $27-\mathrm{km}$ and $9-\mathrm{km}$ domains, respectively. Cumulus parameterization is used for the 27- and 9-km domains, but is turned off for the 
Table 1 Breakdown of the percentage of August 2006 total rainfall in the analysis region associated with MCSs

\begin{tabular}{lrr}
\hline Classification & WRF (\%) & CMORPH (\%) \\
\hline \% of August 2006 total rainfall associated with all MCSs & 82 & 90 \\
\% of August total 2006 rainfall associated with daytime MCS genesis $<1000 \mathrm{~km}$ away & 42 & 69 \\
\% of August 2006 total rainfall associated with nighttime MCS genesis $<1000 \mathrm{~km}$ away & 23 & 1 \\
\% of August 2006 total rainfall associated with MCS genesis $>1000 \mathrm{~km}$ away & 17 & 20 \\
\hline
\end{tabular}

3-km domain. Model output is saved every 30-minutes and analysis is conducted using the 3-km domain output.

The vast majority of nocturnal rainfall over the southwestern Sahel between $11^{\circ} \mathrm{N}-14^{\circ} \mathrm{N}$ is associated with propagating MCSs. Estimates from the $3-\mathrm{km}$ model output and CMORPH observations indicate over $90 \%$ of the nighttime rainfall is associated with MCSs (Fig. 14), consistent with estimates from other studies over West Africa (Le Barbé and Lebel 1997; Mohr et al. 1999; Diongue et al. 2002; Mathon et al. 2002; Mohr 2004; Fink et al. 2006). A comprehensive breakdown of the MCS activity based on the time of day and location of MCS genesis reveals that a high percentage (70-90\%) of nocturnal rainfall is associated with MCSs that originate in the afternoon upstream to the north and east relatively close by (within $1000 \mathrm{~km}$ distance) over the Sahel in an area devoid of significant orography. Thus, the widely accepted idea that most subSaharan northern African MCSs owe their existence to significant topographic features (e.g., Tetzlaff and Peters 1988; Laing and Fritsch 1993; Hodges and Thorncroft 1997; Fink et al. 2006; Laing et al. 2008) does not apply here, and it cannot explain the formation of the MCSs responsible for the nocturnal rainfall over this region. Instead, it is the interaction between the Sahel ITF and atmospheric synoptic conditions over the gradual-sloping terrain of the southern Niger Damergou Gap and Koutous Plateau that is responsible for the afternoon generation of the MCSs over the central Sahel (i.e., $14^{\circ} \mathrm{N}-17^{\circ} \mathrm{N}$ ) that results in downstream nocturnal rainfall maxima over the southern Sahel (i.e., $11^{\circ} \mathrm{N}-14^{\circ} \mathrm{N}$ ).

The Sahel ITF, which is similar to drylines elsewhere in the world (Schaefer 1986), is shown to exhibit a strong diurnal cycle in the northern and central Sahel. Daytime surface heating promotes turbulent mixing in the PBL and, depending on the strength of the surface warming and depth of the low-level moist layer near the surface, determines when and how far equatorward the ITF moves during the day. As the moist layer becomes vertically mixed, the moisture frontal boundary shifts southward across the Sahel during the afternoon, accompanied by a deepening of the PBL over the southern and central Sahel and an afternoon reversal in the low-level meridional flow from southerly to northerly which can enhance low-level meridional wind convergence to trigger MCS genesis.
Whether or not MCSs form in the afternoon depends in part upon whether the PBL height has sufficiently grown so that the vertical mixing extends to or above the LFC. In the case of our analysis region (Fig. 1), all 9 MCS events are associated with PBL heights extending above the LFC (Fig. 6) over the southern Sahel of Niger a few hours prior to genesis.

MCS genesis also depends upon other atmospheric conditions. For our analysis region, afternoon MCS genesis is primarily (in 6 of 9 MCS events) associated with the presence of a mid-tropospheric disturbance to the east of the southern Niger genesis location prior to genesis with zonal phase speeds ranging between 5 and $9 \mathrm{~m} \mathrm{~s}^{-1}$. Circulation associated with this disturbance influences environmental conditions by enhancing the mid-level northerly flow of drier air over southern Niger, associated with stronger instability (Fig. 5). Additionally, the vertical wind shear in the lowest 3-km of the atmosphere strengthens to levels conducive for the development of mid-level rotation and mesocyclones, while further enhancing the low-level wind convergence for 7 of the 9 events.

MCSs with nighttime genesis that originate within $1000 \mathrm{~km}$ (2 events) and MCSs with genesis more than $1000 \mathrm{~km}$ away (5 events) are also evaluated. These events contribute about $20 \%$ of the total nocturnal rainfall in the model and a little more $(\sim 40 \%)$ in CMORPH for our analysis region. Synoptic forcing is important for both, as mid-tropospheric disturbances in the southern and northern disturbance tracks across the continent are common. However, the ITF appears to be influential for only 2 of the cases. One of these MCSs originates in the afternoon over western Chad around $13^{\circ} \mathrm{N}$ and exhibits common traits associated with the ITF, including the low-level meridional flow reversal in the afternoon prior to genesis (Fig. 12c). Additionally, intensification of this system $24 \mathrm{~h}$ later also appears to be aided by the subsequent day's ITF farther downstream. For the other MCS, the ITF is not associated with its nighttime genesis, but it is associated with its intensification on the following afternoon (Fig. 10h). Whether the ITF is influential in these cases depends upon the proximity of the frontal boundary to the MCS. The results here suggest that if they are not located within $2-3^{\circ}$ of latitude of one another, the ITF will have less direct influence on 


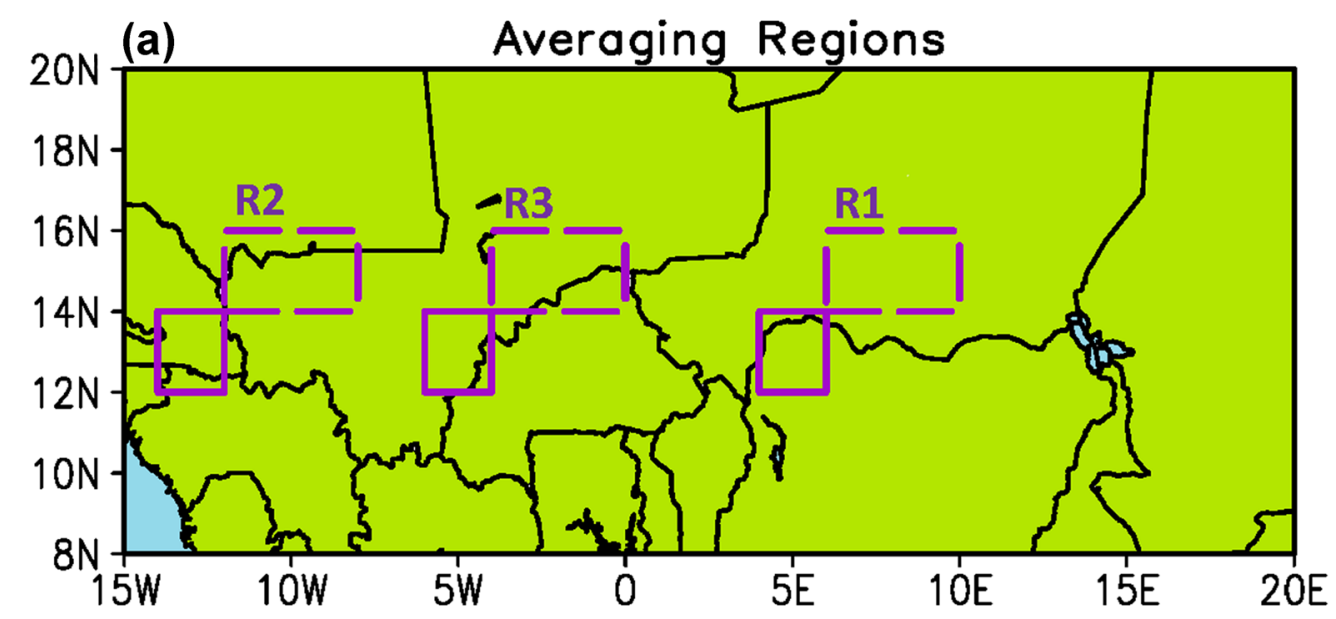

(b) R1 Precipitation

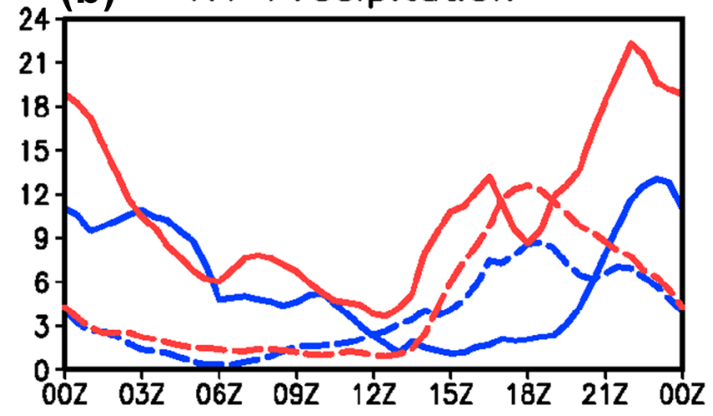

(c) R2 Precipitation

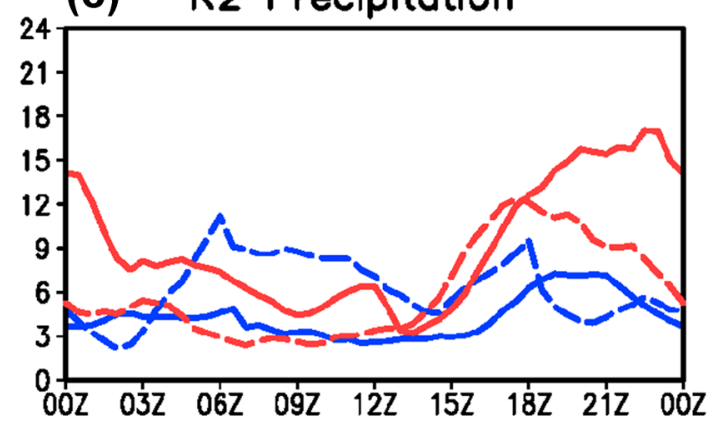

(d) R3 Precipitation

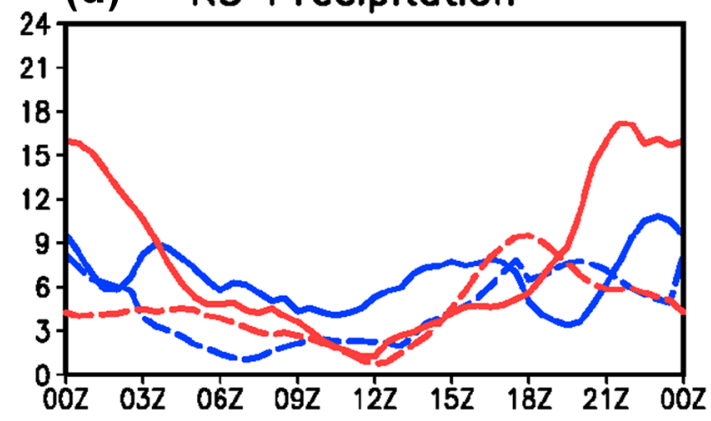

Fig. 15 a Location of southern Sahel averaging regions (solid boxes) and upstream averaging regions (dashed boxes) evaluated. b R1, c R2, and d R3 August 2006 average diurnal cycle of rainfall (mm $\mathrm{day}^{-1}$ ) from the model simulation (red) and CMORPH (blue) for the
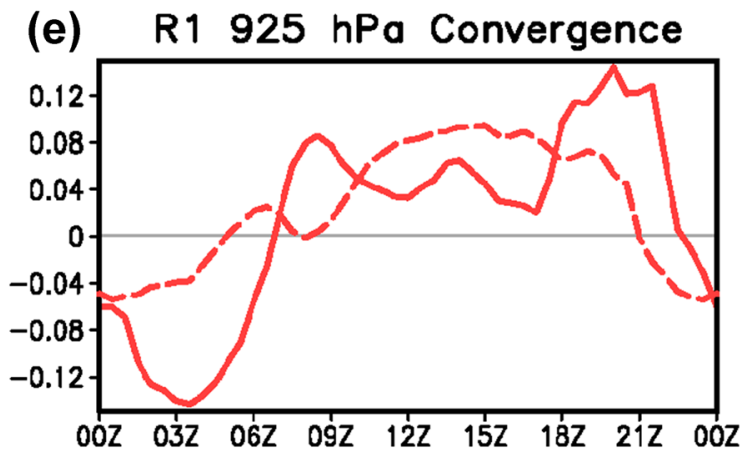

(f) R2 $925 \mathrm{hPa}$ Convergence

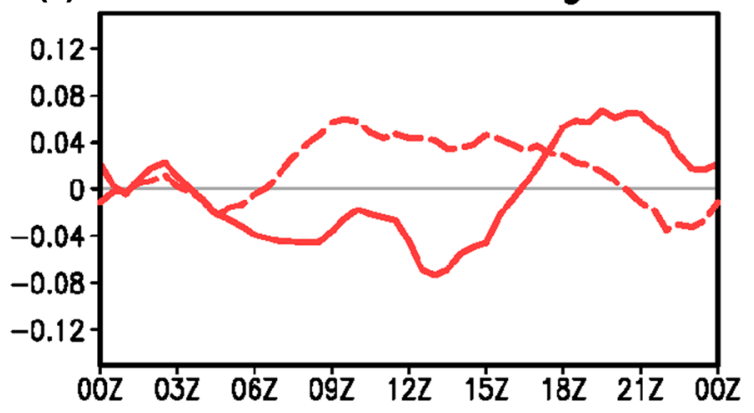

(g) R3 $925 \mathrm{hPa}$ Convergence

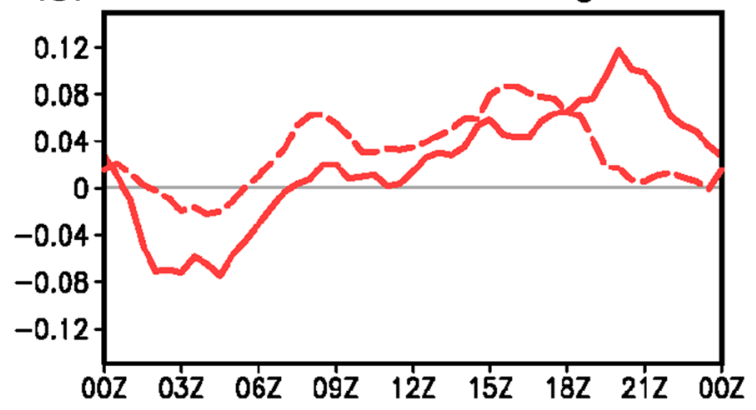

southern Sahel (solid) and upstream (dashed) averaging regions. Also e R1, f R2, and g R3 August 2006 average diurnal cycle of $925 \mathrm{hPa}$ wind convergence $\left(\times 10^{-4} \mathrm{~s}^{-1}\right)$ from the model simulation for the southern Sahel (solid) and upstream (dashed) averaging regions 
the genesis and/or development of an MCS. More work is needed to better understand the robustness of this relationship.

These findings are based on model and observational data for August 2006, and the exact location of this nocturnal precipitation maximum over the Sahel could differ on interannual time scales. For example, Zhang et al. (2016a) demonstrate that, while the summertime nocturnal rainfall maximum is easily identifiable for 2006, it is harder to identify in the TRMM 1998-2013 climatology presumably because of year-to-year variations. This suggests that the location of the ITF in the Sahel is an important factor determining where the nocturnal rainfall will occur. If the frontal boundary is located farther north, then the nocturnal precipitation maximum is also likely to be located farther north, and vice versa. Future work needs to provide a better understanding of interannual variations of the ITF across the Sahel in order to improve our understanding of nocturnal rainfall over the Sahel.

Acknowledgements This work was funded by NSF Award \#1444505. The authors acknowledge the Texas Advanced Computing Center (TACC) at The University of Texas at Austin for providing HPC and database resources that have contributed to the research results reported within this paper. URL: http://www.tacc.utexas.edu. The Grid Analysis and Display System software (GrADS) developed at COLA/IGES was used for generating the figures.

Open Access This article is distributed under the terms of the Creative Commons Attribution 4.0 International License (http:// creativecommons.org/licenses/by/4.0/), which permits unrestricted use, distribution, and reproduction in any medium, provided you give appropriate credit to the original author(s) and the source, provide a link to the Creative Commons license, and indicate if changes were made.

\section{References}

Benjamin SG, Carlson TN (1986) Some effects of surface heating and topography on the regional severestorm environment. Part 1: three dimensional simulations. Mon Wea Rev 114:307-329. doi:10.1175/1520-0493(1986)114<0307:SEOSHA > 2.0.CO;2

Berry GJ, Thorncroft CD (2005) Case study of an intense easterly wave. Mon Wea Rev 133:752-766. doi:10.1175/MWR2884.1.

Berry GJ, Thorncroft CD (2012) African easterly wave dynamics in a mesoscale numerical model: the upscale role of convection. $\mathrm{J}$ Atmos Sci 69:1267-1283. doi:10.1175/JAS-D-11-099.1

Berry GJ, Thorncroft CD, Hewson T (2007) African easterly waves during 2004 - Analysis using objective techniques. Mon Wea Rev 135:1251-1267. doi:10.1175/MWR3343.1

Birch CE, Marsham JH, Parker DJ, Taylor CM (2014a) The scale dependence and structure of convergence fields preceding the initiation of deep convection. Geophys Res Lett 41:4769-4776. doi:10.1002/2014GL060493

Birch CE, Parker DJ, Marsham JH, Copsey D, Garcia-Carreras L (2014b) A seamless assessment of the role of convection in the water cycle of the West African Monsoon. J Geophys Res 119:2890-2912. doi:10.1002/2013JD020887
Burpee RW (1972) The origin and structure of easterly waves in the lower troposphere of North Africa. J Atmos Sci 29:77-90. doi:10.1175/1520-0469(1972)029<0077:TOASOE > 2.0.CO;2

Burpee RW (1974) Characteristics of North African easterly waves during the summers of 1968 and 1969. J Atmos Sci 31:15561570. doi:10.1175/1520-0469(1974)031<1556:CONAEW >2.0 $\mathrm{CO} ; 2$

Carlson TN, Benjamin SG, Forbes GS (1983) Elevated mixed layers in the regional severe stormenvironment: conceptual model and case studies. Mon Wea Rev 111:1453-1473. doi:10.1175/1520-0493(1983)111<1453:EMLITR > 2.0.CO;2

Chen F, Dudhia J (2001) Coupling an advanced land-surface/ hydrology model with the Penn State/ NCAR MM5 modeling system. Part I: Model description and implementation. Mon Wea Rev 129: 569-585. doi:10.1175/1520-0493(2001)129<0569:CAALS $\mathrm{H}>2.0 . \mathrm{CO} ; 2$.

Cook KH (1999) Generation of the African Easterly jet and its role in determining West African precipitation. J Climate 12:11651184. doi:10.1175/1520-0442(1999)012<1165:GOTAEJ $>2.0$ $\mathrm{CO} ; 2$

Crétat, J, Vizy EK, Cook KH (2014) How well are daily intense rainfall events captured by current climate models over Africa? Clim Dyn 42:2691-2711. doi:10.1007/s/00382-013-1796-7

Crétat J, Vizy EK, Cook KH (2015) The relationship between African easterly waves and daily rainfall over West Africa. Observations and regional climate simulations. Clim Dyn 44:385-404. doi:10.1007/s00382-014-2120-x.

Dai A (2001) Global precipitation and thunderstorm frequencies. Part II: Diurnal variations. J Clim 14:1112-1128. doi:10.1175/1520-0442(2001)014<1112:GPATFP > 2.0.CO;2

Dee DP, Uppala SM, Simmons AJ et al (2011) The ERA-Interim reanalysis: configuration and performance of the data assimilation system. Q J Roy Meteorol Soc 137:553-597. doi:10.1002/qj.828

Desbois M, Kayiranga T, Gnamien B, Guessous S, Picon L (1988) Characterization of some elements of the Sahelian climate and their interannual variations for July 1983, 1984, and 1985 from the analysis of Meteosat ISCCP data. J Climate 9:867-904. doi:10.1175/1520-0442(1988)001<0867:COSEOT>2.0.CO;2

Diedhiou A, Janicot S, Viltard A, de Félice P, Laurent H (1999) Easterly wave regimes and associated convection over West Africa and the tropical Atlantic: Results from the NCEP/NCAR and ECMWF reanalyses. Clim Dyn 15:795-822. doi:10.1007/ s003820050316

Diongue A, Lafore J-P, Redelsperger J-L, Roca R (2002) Numerical study of a Sahelian synoptic weather system: initiation and mature stages of convection and its interactions with the large-scale dynamics. Q J Roy Meteorol Soc 128:1899-1927. doi: $10.1256 / 003590002320603467$

Dudhia J (1989) Numerical study of convection observed during the winter monsoon experiment using a mesoscale two-dimensional model. J Atmos Sci 46:3077-3107. doi:10.1175/1520-0469(1989)046<3077:NSOCOD>2.0.CO;2

Duvel J-P (1989) Convection over tropical Africa and the Atlantic Ocean during northern summer. Part I: Interannual and diurnal variations. Mon Wea Rev 117:2782-2799. doi:10.1175/1520-0493(1989)117<2782:COTAAT > 2.0.CO;2

Eldridge RH (1957) A synoptic study of West African disturbance lines. Q J Roy Meteorol Soc 83:303-314. doi:10.1002/ qj. 49708335704

Fink AH, Reiner A (2003) Spatiotemporal variability of the relation between African easterly waves and West African squall lines in 1998 and 1999. J Geophys Res 108:4332. doi:10.1029/200 2JD002816

Fink AH, Vincent DG, Ermert V (2006) Rainfall types in the West African Sudanian zone during the summer monsoon 2002. Mon Wea Rev 134:2143-2164. doi:10.1175/MWR3182.1 
Grodsky SA, Carton JA, Nigam S (2003) Near surface westerly wind jet in the Atlantic ITCZ. Geophys Res Lett 30:2009. doi:10.1029 /2003GL017867

Hamilton RA, Archbold JW (1945) Meteorology of Nigeria and adjacent territory. Q J Roy Meteorol Soc 71:231-264. doi:10.1002/ qj. 49707130905

Hane CE (2004) Quiescent and synoptically-active drylines: A comparison based upon case studies. Meteorol Atmos Phys 86:195211. doi:10.1007/s00703-003-0026-y

Hodges KI, Thorncroft CD (1997) Distribution and statistics of African mesoscale convective weather systems based on ISCCP METEOSAT imagery. Mon Wea Rev 125: 2821-2837. doi:10.1175/1520-0493(1997)125<2821:DASOAM>2.0.CO;2

Hong S-Y, Noh Y, Dudhia J (2006) A new vertical diffusion package with an explicit treatment of entrainment processes. Mon Wea Rev 134:2318-2341. doi:10.1175/MWR3199.1

Houze RA Jr (1993) Cloud dynamics. Academic, San Diego, p 573

Hsieh J-S, Cook KH (2005) Generation of African easterly wave disturbances: Relationship to the African easterly jet. Mon Wea Rev 133:1311-1327. doi:10.1175/MWR2916.1

Hsieh J-S, Cook KH (2007) A study of the energetics of African easterly waves using a regional climate model. J Atmos Sci 64:421440. doi:10.1175/JAS3851.1

Hsieh J-S, Cook KH (2008) On the instability of the African easterly jet and the generation of African waves: reversals of the potential vorticity gradiet. J Atmos Sci 65:2130-2151. doi:10.1175/ JAS2552.1

Huffman GJ, Adler RF, Bolvin DT, Gu G, Nelkin EJ, Bowman KP, Hong Y, Stocker EF, Wolff DB (2007) The TRMM multisatellite precipitation analysis (TMPA): quasi-global, multiyear, combined-sensor precipitation estimates at fine scales. J Hydrometeorol 8:38-55. doi:10.1175/JHM560.1

Joyce R, Janowiak J, Arkin PA, Xie P (2004) CMORPH: A method that produces global precipitation estimates from passive microwave and infrared data at high spatial and temporal resolution. $\mathrm{J}$ Hydrometeor 5:487-503. doi:10.1175/1525-7541(2004)005,0487:CAMTPG.2.0.CO;2

Kain JS (2004) The Kain-Fritsch convective parameterization: An update. J Appl Meteor 43:170-181. doi:10.1175/1520-0450(2004)<0170:TKCPAU>2.0.CO;2

Kalapureddy MCR, Lothon M, Campistron B, Lohou F, Saïd F (2010) Wind profiler analysis of the African easterly jet in relation with the boundary layer and Saharan heat-low. Q J Roy Meteorol Soc 136:77-91. doi:10.1002/qj.494

Laing AG, Carbone R, Levizzani V, Tuttle J (2008) The propagation and diurnal cycles of deep convection in northern tropical Africa. Q J Roy Meteorol Soc 134:93-109. doi:10.1002/qj.194

Laing AG, Fritsch JM (1993) Mesoscale convective complexes in Africa. Mon Wea Rev 121:2254-2263. doi:10.1175/1520-0493(1993)121<2254:MCCIA > 2.0.CO;2

Laing AG, Fritsch JM, Negri AJ (1999) Contribution of mesoscale convective complexes to rainfall in Sahelian Africa: estimates from geostationary infrared and passive microwave data. J Appl Meteorol 38:957-964. doi:10.1175/1520-0450(1999)038<0957:COMCCT>2.0.CO;2

Laing AG, Trier SB, Davis CA (2012) Numerical simulation of episodes of organized convection in tropical northern Africa. Mon Wea Rev 140:2874-2886. doi:10.1175/MWR-D-11-00330.1

Laurent H, D'Amato N, Lebel T (1998) How important is the contribution of the mesoscale convective complexes to the Sahelian rainfall? Phys Chem Earth 23:629-633. doi:10.1016/ S0079-1946(98)00099-8

Le Barbé L, Lebel T (1997) Rainfall climatology of the HAPEXSahel region during the years 1950-1990. J Hydrol 188-189:4373. doi:10.1016/S0033-1694(96)03154-X
Marsham JH, Dixon N, Garcia-Carreras L, Lister G, Parker DJ, Knippertz P, Birch C (2013) The role of moist convection in the West African monsoon system: insights from continental-scale convection-permitting simulations. Geophys Res Lett 40:18431849. doi:10.1002/grl.50347

Mathon V, Laurent H, Lebel T (2002) Mesoscale convective system rainfall in the Sahel. J Appl Meteorol 41:1081-1092. doi:10.1175/1520-0450(2002)041<1081:MCSRIT>2.0.CO;2

Maurer V, Bischoff-Gauß I, Kalthoff N, Gantner L, Roca R, Panitz HJ (2016) Initiation of deep convection in the Sahel in a convectionpermitting climate simulation for northern Africa. Q J R Meteorol Soc. doi:10.1002/qj.2966 (accepted author manuscript)

Mlawer EJ, Taubman SJ, Brown PD, Iacono MJ, Clough SA (1997) Radiative transfer for inhomogeneous atmosphere: RRTM, a validated correlated-k model for the longwave. J Geophys Res 102:16663-16682. doi:10.1029/97JD00237

Mohr KI (2004) Interannual, monthly, and regional variability in the wet season diurnal cycle of precipitation in sub-Saharan Africa. J Climate 17:2441-2453. doi:10.1175/1520-0442(2004)017<2441:IMARVI>2.0.CO;2

Mohr KI, Famiglietti JS, Zipser EJ (1999) The contribution to tropical rainfall with respect to convective system type, size, and intensity estimated from the 85-GHz ice-scattering signature. J Appl Meteorol 38:596-606. doi:10.1175/1520-0450(1999)038<0596:TCT $\mathrm{TRW}>2.0 . \mathrm{CO} ; 2$

Mohr KI, Thorncroft CD (2006) Intense convective systems in West Africa and their relationship to the African easterly jet. Q J Roy Meteorol Soc 132:163-176. doi:10.1256/qj.05.55

Mohr KI, Zipser EJ (1996) Mesoscale convective systems defined by their $85-\mathrm{GHz}$ ice scattering signature: Size and intensity comparison over tropical oceans and continents. Mon Wea Rev 124:2417-2437. doi:10.1175/1520-0493(1996)124<2417:MCS DBT > 2.0.CO;2

Nesbitt SW, Zipser EJ (2003) The diurnal cycle of rainfall and convective intensity according to three years of TRMM measurements. J Climate 16:1456-1475. doi:10.1175/1520-0442\&a>2.0.CO;2

Ogura Y, Juang H, Zhang K, Soong S (1982) Possible triggering mechanisms for severe storms in SESAME-AVE IV (9-10 May 1979). Bull Am Meteorol Soc 63:503-515

Parker DJ, Burton RR, Diongue-Niang A, Ellis RJ, Felton M, Taylor CM, Thorncroft CD, Bessemoulin P, Tompkins AM (2005b) The diurnal cycle of the West African monsoon circulation. Q J Roy Meteorol Soc 131:2839-2860. doi:10.1256/qj.04.52

Parker DJ, Thorncroft CD, Burton RR, Diongue-Niang A (2005a) Analysis of the African easterly jet using aircraft observations from the JET2000 experiment. Q J Roy Meteorol Soc 131:14611482. doi:10.1256/qj.03.189

Pearson KJ, Lister GMS, Birch CE, Allan RP, Hogan RJ, Woolnough SJ (2013) Modelling the diurnal cycle of tropical convection across the "Grey Zone". Q J R Meteorol Soc 140:491-499. doi:10.1002/qj.2145

Peters M, Tetzlaff G (1988) The structure of West African squall lines and their environmental moisture budget. Meteorol Atmos Phys 39:74-84. doi:10.1007/BF01041933

Pfeifroth U, Trentmann J, Fink AH, Ahrens B (2016) Evaluating satellite-based diurnal cycles of precipitation in the African tropics. J Appl Meteorol Climatol 55:23-39. doi:10.1175/ JAMC-D-15-0065.1

Pu B, Cook KH (2010) Dynamics of the West African westerly jet. J Climate 23:6263-6276. doi:10.1175/2010JCLI3648.1

$\mathrm{Pu}$ B, Cook KH (2012) Role of the West African westerly jet in Sahel rainfall variations. J Climate 25:2880-2896. doi:10.1175/ JCLI-D-11-00394.1

Reed RJ, Norquist DC, Recker EE (1977) The structure and properties of African wave disturbances as observed 
during Phase III of GATE. Mon Wea Rev 105:317-333. doi:10.1175/1520-0493(1977)105<0317:TSAPOA > 2.0.CO;2

Rhea JO (1966) A study of thunderstorm formation along drylines. J Appl Meteor 5:58-63. doi:10.1175/1520-0450(1966)005<0058:ASOTFA > 2.0.CO;2

Rowell DP, Milford JR (1993) On the generation of African squall lines. J Climate 6:1181-1193. doi:10.1175/1520-0442(1993)006<1181:OTGOAS > 2.0.CO;2

Schaefer JT (1974) The life cycle of the dryline. J App Meteorol 13:444-449. doi:10.1175/1520-0450(1974)013<0444:TLCOTD $>2.0 . \mathrm{CO} ; 2$

Schaefer JT (1986) The dryline. In: Ray PS (ed) Mesoscale Meteorology and Forecasting. American Meteorological Society, Boston, pp 549-572

Schultz DM, Weiss CC, Hoffman PM (2007) The synoptic regulation of dryline intensity. Mon Wea Rev 135: 1699-1709. doi:10.1175/ MWR3376.1.

Skamarock WC, Klemp JB, Dudhia J, Gill DO, Barker DM, Wang W, Powers JG (2005) A description of the advanced research WRF version 2. NCAR/TN-408 + STR, 88 pp., [Available from NCAR Information Services, P.O. Box 3000, Boulder, CO 80307.]

Taylor CM, Birch CE, Parker DJ, Dixon N, Guichard F, Nikulin G, Lister GMS (2013) Modeling soil moisture-precipitation feedback in the Sahel: Importance of spatial scale versus convective parameterization. Geophys Res Lett 40:6213-6218. doi:10.1002 /2013GL058511

Tetzlaff G, Peters M (1988) A composite study of early summer squall lines and their environment over West Africa. Meteorol Atmos Phys 38:153-163. doi:10.1007/BF01029779.

Thompson G, Rasmussen RM, Manning K (2004) Explicit forecasts of winter precipitation using an improved bulk microphysics scheme. Part I: Description and sensitivity analysis. Mon Wea
Rev 132:519-542. doi:10.1175/1520-0493(2004)132<0519:EFO WPU>2.0.CO;2.

Trier SB, Chen F, Manning KW (2004) A study of convective initiation in a mesoscale model using high-resolution land surface initial conditions. Mon Wea Rev 132:2954-2976. doi:10.1175/ MWR2839.1

Trier SB, Romine GS, Ahuevych DA (2015) Mesoscale thermodynamic influences on convection initiation near a surface dryline in a convection-permitting ensemble. Mon Wea Rev 143:37263753. doi:10.1175/MWR-D-15-0133.1

Vizy EK, Cook KH (2009) Tropical storm development from African easterly waves in the eastern Atlantic: a comparison of two successive waves using a regional model as part of NASA AMMA 2006. J Atmos Sci 66:3313-3334. doi:10.1175/2009JAS3064.1

Vizy EK, Cook KH, Chimphamba J, McCusker B (2015) Projected changes in Malawi's growing season. Clim Dyn 45:1673-1698. doi:10.1007/s00382-014-2424-x

Vizy EK, Cook KH, Crétat J, Neupane N (2013) Projections of a wetter Sahel in the 21st century from global and regional models. J Climate 26:4664-4687. doi:10.1175/JCLI-D-12-00533.1

Williams RJ (1976) Surface parameters associated with tornadoes. Mon Wea Rev 104:540-545. doi:10.1175/1520-0493(1976)104<0540:SPAWT>2.0.CO;2

Wu M-L, Reale O, Schubert SD (2013) A characterization of African easterly waves on 2.5-6-day and 6-9-day time scales. J Climate 26:6750-6774. doi:10.1175/JCLI-D-12-00336.1

Zhang G, Cook KH, Vizy EK (2016a) The diurnal cycle of warm season rainfall over West Africa. Part I: observational analysis. J Climate. doi:10.1175/JCLI-d-15-0874.1

Zhang G, Cook KH, Vizy EK (2016b) The diurnal cycle of warm season rainfall over West Africa. Part II: convection-permitting simulations. J Climate. doi:10.1175/JCLI-d-15-0875.1 